\title{
The Interaction Between Shield, Ground and Tunnel Support in TBM Tunnelling Through Squeezing Ground
}

\section{Journal Article}

Author(s):

Ramoni, Marco; Anagnostou, Georg

Publication date:

2011-01

Permanent link:

https://doi.org/10.3929/ethz-b-000030014

Rights / license:

In Copyright - Non-Commercial Use Permitted

Originally published in:

Rock Mechanics and Rock Engineering 44(1), https://doi.org/10.1007/s00603-010-0103-8 


\title{
The Interaction Between Shield, Ground and Tunnel Support in TBM Tunnelling Through Squeezing Ground
}

\author{
M. Ramoni - G. Anagnostou
}

Received: 15 January 2010/Accepted: 14 May 2010/Published online: 15 June 2010

(C) Springer-Verlag 2010

\begin{abstract}
When planning a TBM drive in squeezing ground, the tunnelling engineer faces a complex problem involving a number of conflicting factors. In this respect, numerical analyses represent a helpful decision aid as they provide a quantitative assessment of the effects of key parameters. The present paper investigates the interaction between the shield, ground and tunnel support by means of computational analysis. Emphasis is placed on the boundary condition, which is applied to model the interface between the ground and the shield or tunnel support. The paper also discusses two cases, which illustrate different methodical approaches applied to the assessment of a TBM drive in squeezing ground. The first case history-the Uluabat Tunnel (Turkey)—mainly involves the investigation of TBM design measures aimed at reducing the risk of shield jamming. The second case history-the Faido Section of the Gotthard Base Tunnel (Switzerland)_deals with different types of tunnel support installed behind a gripper TBM.
\end{abstract}

Keywords Tunnel boring machine .

Mechanized tunnelling · Squeezing ground ·

Shield jamming · Tunnel support · Yielding support .

Numerical investigation - Steady state method

Abbreviation
$\begin{array}{ll}A_{\mathrm{ss}} & \text { Cross-sectional area of the steel set } \\ b & \text { Steel set spacing } \\ b^{\prime} & \text { Steel set clear distance } \\ c & \text { Cohesion of the ground }\end{array}$

M. Ramoni ( $₫) \cdot$ G. Anagnostou ETH Zurich, Zurich, Switzerland e-mail: marco.ramoni@igt.baug.ethz.ch

\begin{tabular}{|c|c|}
\hline$C$ & Circumference \\
\hline$C_{\mathrm{ce}}$ & Arc length of the deformable concrete elements \\
\hline$C_{\mathrm{sc}}$ & Arc length of the shotcrete ring \\
\hline$C_{\mathrm{ss}}$ & Circumference of the steel set \\
\hline$D$ & Boring diameter \\
\hline$d_{1}$ & Thickness of the shotcrete layer \\
\hline$d_{2}$ & $\begin{array}{l}\text { Height of the deformable elements (yielding } \\
\text { support) }\end{array}$ \\
\hline$e$ & Extrusion rate of the core \\
\hline$E$ & Young's modulus of the ground \\
\hline$E_{\mathrm{sc}}$ & Young's modulus of the shotcrete \\
\hline$E_{\mathrm{ss}}$ & Young's modulus of the steel \\
\hline$F$ & Thrust force \\
\hline$F_{\mathrm{b}}$ & Boring thrust force \\
\hline$f_{\mathrm{c}}$ & Uniaxial compressive strength of the ground \\
\hline$f_{\mathrm{c}, \mathrm{ce}}$ & $\begin{array}{l}\text { Maximum compressive stress of the deformable } \\
\text { concrete elements }\end{array}$ \\
\hline$f_{\mathrm{c}, \mathrm{sc}}$ & Uniaxial compressive strength of the shotcrete \\
\hline$f_{\mathrm{y}, \mathrm{ss}}$ & Yield stress of the steel \\
\hline$F_{\mathrm{i}}$ & Installed thrust force \\
\hline$f_{1}$ & $\begin{array}{l}\text { Boundary condition for the simulation of the } \\
\text { tunnel support }\end{array}$ \\
\hline$F_{\mathrm{r}}$ & Required thrust force \\
\hline$f_{\mathrm{s}}$ & $\begin{array}{l}\text { Boundary condition for the simulation of the } \\
\text { shield }\end{array}$ \\
\hline$H$ & Depth of cover \\
\hline$K_{1}$ & Stiffness of the lining \\
\hline$K_{\mathrm{s}}$ & Stiffness of the shield \\
\hline$l$ & Length of a critical geological zone \\
\hline$L$ & Length of the shield \\
\hline$N$ & Hoop force \\
\hline$N_{\mathrm{ce}}$ & Hoop force in the deformable concrete elements \\
\hline$n_{\mathrm{ce}}$ & Number of deformable concrete elements \\
\hline$N_{\mathrm{f}}$ & Friction loop resistance \\
\hline$n_{\mathrm{f}}$ & Number of friction loops \\
\hline
\end{tabular}


$N_{\max } \quad$ Yield load of the steel set

$N_{\text {sc }} \quad$ Hoop force in the shotcrete ring

$N_{\mathrm{y}} \quad$ Yield load of the sliding connections

$p \quad$ Ground pressure

$p_{\mathrm{s}} \quad$ Average ground pressure acting upon the shield

$r \quad$ Radial co-ordinate (distance from the tunnel axis)

$R \quad$ Tunnel radius

$R_{\mathrm{F}, \mathrm{T}} \quad$ Reaction force

$s \quad$ Step length (step-by-step calculations)

$t \quad$ Time

$T \quad$ Torque

$u \quad$ Radial displacement of the ground (at the tunnel boundary)

$u_{1} \quad$ Radial displacement of the lining

$v \quad$ Advance rate

$y \quad$ Axial co-ordinate (distance behind the tunnel face)

$y^{\prime} \quad$ Position of the tunnel face

$\Delta R \quad$ Radial gap size

$\varepsilon_{\mathrm{ss}, \max }$ Failure strain of the steel

$\varepsilon_{\mathrm{t}} \quad$ Hoop strain

$\varepsilon_{\mathrm{t}, \mathrm{ce}} \quad$ Hoop strain of the deformable concrete elements

$\varepsilon_{\mathrm{t}, \mathrm{sc}} \quad$ Hoop strain of the shotcrete

$\varepsilon_{\mathrm{t}, \mathrm{ss}} \quad$ Hoop strain of the steel set

$\varphi \quad$ Angle of internal friction of the ground

$\mu \quad$ Shield skin friction coefficient

$v \quad$ Poisson's ratio of the ground

$\sigma \quad$ Stress

$\sigma_{0} \quad$ Initial stress

$\sigma_{1} \quad$ Maximum principal stress

$\sigma_{3} \quad$ Minimum principal stress

$\sigma_{\mathrm{rr}} \quad$ Radial stress

$\sigma_{\text {ry }} \quad$ Shear stress

$\sigma_{\mathrm{t}} \quad$ Hoop stress

$\sigma_{\mathrm{t}, \mathrm{ce}} \quad$ Hoop stress in the deformable concrete elements

$\sigma_{\mathrm{t}, \mathrm{sc}} \quad$ Hoop stress in the shotcrete

$\sigma_{\mathrm{t}, \mathrm{ss}} \quad$ Hoop stress in the steel set

$\sigma_{\mathrm{tt}} \quad$ Tangential stress

$\sigma_{\text {yy }} \quad$ Axial stress

$\psi \quad$ Dilatancy angle of the ground

\section{Introduction}

Squeezing ground represents a challenging condition for operating tunnel boring machines (TBMs), because even relatively small convergences of up to $10-20 \mathrm{~cm}$ (that would not really be problematic in conventional tunnelling) may lead to difficulties in the machine (sticking of the cutter head, jamming of the shield) or in the back-up area (e.g., jamming of the back-up equipment, inadmissible convergences of the bored profile, damage to the tunnel support). "Squeezing" refers to the phenomenon of large long-term deformations of the bored profile due to the overstressing of the ground surrounding the tunnel. It occurs mostly in weak rocks with a high deformability and a low strength and often in combination with a high overburden and a high water pressure (Barla 2001; Kovári 1998). Phyllites, schists, serpentinites and claystones are among the rocks often exhibiting heavily squeezing behaviour. As experienced, e.g., in some stretches of the Gotthard Base Tunnel (Switzerland), relevant deformations for TBM tunnelling may occur also in relatively hard but fractured rocks (e.g., gneisses), particularly if encountered at great depths.

An extended review of the literature concerning experience with TBMs in squeezing ground, the possible technological improvement of the common TBM types (i.e., gripper, single and double shielded TBM), the development of alternative machine concepts, the possible measures for coping with squeezing ground and the development of deformable lining systems that might cope better with high ground pressures can be found in Ramoni and Anagnostou (2010b).

When evaluating the feasibility of a TBM drive in squeezing ground, it is of paramount importance to understand the mechanisms governing the interaction between shield, ground and tunnel support. For the design of the TBM and the tunnel support, a series of issues must be investigated in relation to the ground pressure $p$ (acting upon the cutter head, the shield and the lining), the convergence of the tunnel wall $u$, the extrusion rate of the core $e$, the required thrust force $F$ and the torque $T$ as well as the resulting reaction forces $R_{\mathrm{F}, \mathrm{T}}$ (Fig. 1). All of these parameters may also depend on the advance rate $v$ or on the duration of any excavation standstill that may take place.

A number of different analytical, empirical and numerical approaches have been proposed in the literature for the quantitative assessment of these parameters (Sect. 2). The present paper follows a numerical approach, addressing the question of the boundary conditions that need to be applied in order to simulate the interface between ground and shield or tunnel support adequately (Sect. 3) and discussing the structural interplay between these system components by means of computational results (Sect. 4). The paper also presents two examples of real world applications which illustrate possible methodical approaches to the assessment of a TBM drive in squeezing ground (Sects. 5, 6). The first case history-the Uluabat Tunnel (Turkey) - mainly concerns the investigation of TBM design measures with the aim of reducing the risk of shield jamming. The second case history-the Faido Section of the Gotthard Base Tunnel (Switzerland) - deals with the different types of tunnel support installed behind a gripper TBM. A 
Fig. 1 Critical parameters for a gripper TBM (a) and a single shielded TBM (b) in squeezing ground

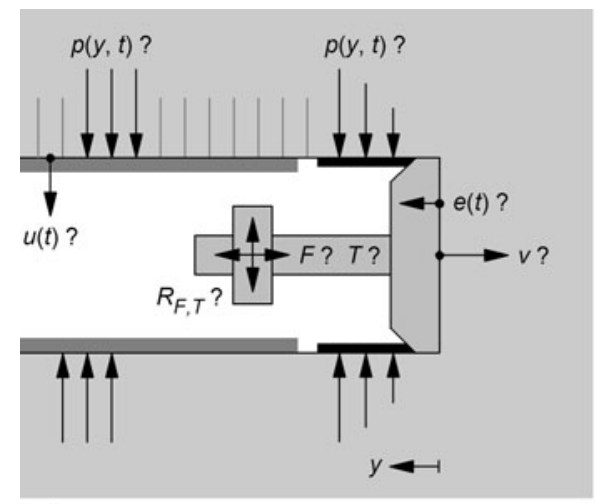

(a)

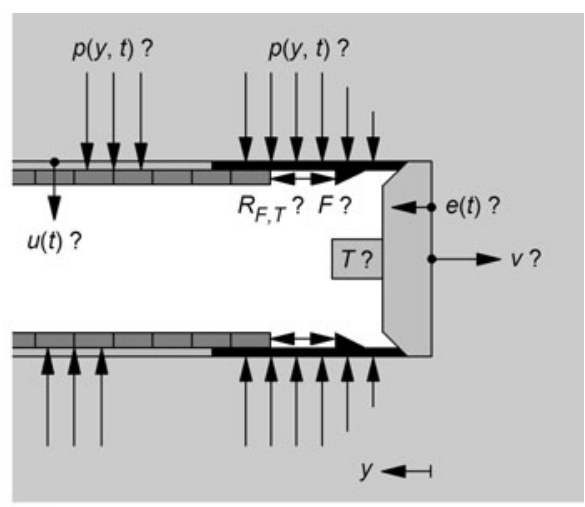

(b) considerable degree of engineering judgement is required in cases such as this-in contrast to shielded TBMs where the support is, as a rule, pre-determined (precast segmental lining).

\section{Design and Analysis Methods}

\subsection{Closed-Form Solutions}

The method of characteristic lines is the simplest and widely used analysis method in tunnelling. It has also been used by Kovári (1986a, b) with respect to some of the issues of TBM tunnelling in squeezing ground. Vogelhuber (2007) later applied the convergence-confinement method for investigating the crossing of a shear zone at great depth with a double shielded TBM of $10 \mathrm{~m}$ diameter. He was thereby able to differentiate between the short-term and long-term behaviour of the ground. The method of characteristic lines is still used today for analysing the interaction between ground and support also with regard to deformable segmental linings of shield-driven tunnels through squeezing rock (cf., e.g., Billig et al. 2007; Schneider and Spiegl 2008).

The main disadvantage of the method of characteristic lines is that it does not provide the longitudinal distribution of the ground pressure acting upon the shield and the lining. For this purpose, additional assumptions must be introduced. Therefore, for example, Hisatake and Iai (1993) proposed a time-dependent (creep) non-dimensional displacement function for the longitudinal distribution of the radial ground displacements, while Moulton et al. (1995) and Feknous et al. (1996) introduced three-dimensional diagrams that show support pressure as a function of convergence and distance from the tunnel face. Making an a priori assumption about the distribution and magnitude of the ground pressure is an even stronger simplification. This approach was followed by Eisenstein and Rossler (1995), who developed design charts for the operability of double shielded TBMs in gripper mode, as well as by Vigl et al. (1999) in their discussion of the latest developments in double shielded TBMs. On the basis of numerical calculations, Gärber (2003) improved the convergence-confinement method, provided charts for the design of deep tunnels in low permeability saturated porous media and applied the proposed semi-analytical solution method to the back-analysis of the segmental lining for the Nuclear Research Centre Connecting Gallery (Belgium), which was excavated by a single shielded TBM $(D=4.81 \mathrm{~m})$.

\subsection{Empirical Relationships}

Other studies have attempted to get around the drawbacks of analytical solutions by introducing empirical functions based upon field measurements, which describe the longitudinal distribution of the radial displacement of the tunnel boundary. Schubert (2000) showed the effect of the advance rate on tunnel closure in a specific case using the relationships proposed by Sulem et al. (1987) and improved by Sellner (2000). Farrokh et al. (2006), Jafari et al. (2007) and Khademi Hamidi et al. (2008) evaluated ground pressure and thrust force requirement in their empirical investigation into the double shielded TBMs of the Ghomroud Tunnel (Iran, $D=4.50 \mathrm{~m}$ ) and the Nosoud Tunnel (Iran, $D=6.73 \mathrm{~m}$ ).

The performance of TBMs in squeezing ground can also be assessed by evaluating and correlating the operational parameters of the TBM. This was done, e.g., by Kawatani et al. (1999) for the Takisato Tunnel (Japan, double shielded TBM, $D=8.30 \mathrm{~m}$ ) and by Farrokh and Rostami $(2008,2009)$ for the Ghomroud Tunnel (Iran).

In spite of the applications mentioned above, one should bear in mind that the reliability of empirical methods is in general limited, as they are based upon correlations of field data obtained in specific projects with potentially different conditions. 


\subsection{Numerical Investigations}

Axially symmetric or three-dimensional numerical models pay due attention to the spatial stress redistribution in the vicinity of the advancing face, thus eliminating the errors introduced by the assumption of plane strain conditions (Cantieni and Anagnostou 2009) and providing information on the evolution of stresses and deformations in the longitudinal direction as well as allowing a more detailed modelling of the different system components (i.e., ground, TBM, tunnel support) and their interfaces.

The initial results of spatial numerical analyses have already been presented by Lombardi (1981), who discussed the influence of the advance rate on the lining loading for the simplified case of a lining that starts to become loaded $40 \mathrm{~m}$ behind the face. Lombardi's (1981) work dealt with aspects of tunnelling in overstressed rocks from a fundamental point of view. In the majority of cases reported in the literature, however, the numerical investigations have been carried out in the framework of specific TBM projects. So, for example, Lombardi and Panciera (1997) and Panciera and Piccolo (1997) analyzed the feasibility of a double shield TBM drive for the Guadiaro-Majaceite Tunnel (Spain, $D=4.88 \mathrm{~m}$ ) taking account of the effects of advance rate and of time-dependent ground behaviour. Matter et al. (2007) studied the crossing of shear zones by the Wienerwald Tunnel (Austria, single shielded TBM, $D=10.67 \mathrm{~m}$ ) by means of axially symmetric numerical investigations. Fully three-dimensional computational models have been applied by Cobreros et al. (2005) and by Simic (2005) - a study which considers creep effects as well-for the Guadarrama Tunnel (Spain, double shielded TBM, $D=9.51 \mathrm{~m}$ ) and by Graziani et al. (2007a, b), who studied the planned Brenner Base Tunnel (Austria, double shielded TBM, $D=11.00 \mathrm{~m}$ ) within the framework of the TISROCK research project (for general information about TISROCK see John and Schneider 2007). Other projectrelated investigations include those of Wittke et al. (2007), who evaluated the stresses and deformations of the shield structure of the single shielded TBM of the Hallandsas Tunnel (Sweden, $D=10.70 \mathrm{~m}$ ) taking account of seepage flow and dealing with the structural detailing of the shield by making a simplifying a priori assumption that the ground closes the steering gap at a distance of $4 \mathrm{~m}$ behind the working face.

Another group of papers involves numerical investigations, which do not take specific account of the shield in the computational model. For example, Shalabi (2005) carried out a back-analysis of the creep deformations and pressures of the Stillwater Tunnel (USA, $D=3.06 \mathrm{~m}$ ) by assuming that the tunnel is lined up to the face. John and Mattle (2007) analyzed squeezing ground conditions for the Strenger Tunnel (Austria, $D=11.00 \mathrm{~m}$ ) within the previously mentioned "TISROCK" research project. Floria et al. (2008), Amberg (2009) and Lombardi et al. (2009) investigated the effect of advance drainage on ground response for the excavation of the service tunnel of the planned Gibraltar Strait Tunnel between Morocco and Spain $(D=6.50 \mathrm{~m})$. In the first two studies (Floria et al. 2008; John and Mattle 2007) the ground around the shield was regarded as being unsupported, while Amberg (2009) and Lombardi et al. (2009) simulated the shield by applying a support pressure of $1 \mathrm{MPa}$ at the face and at the excavation boundary around the shield. All of these works assessed the feasibility of the TBM drive by comparing the computed radial displacements in the machine area with the size of the radial gap between shield and ground.

Research of a general character, i.e., not related to a specific tunnel project, has been carried out by Ramoni and Anagnostou (2006) and by Schmitt (2009). Schmitt (2009) investigated the behaviour of single shielded TBMs by means of fully three-dimensional, step-by-step simulations of tunnel excavation, thus gaining a valuable insight into the effects of non-uniform convergence and of nonhydrostatic shield and lining loading, while Ramoni and Anagnostou (2006) employed axisymmetric numerical models in order to investigate the effects of thrust force, overboring, shield length and skin friction coefficient between the shield and the ground with respect to the problem of shield jamming.

The numerical solution method of Ramoni and Anagnostou (2006) simulated tunnel excavation by monotonous unloading of the tunnel boundary from its initial value $\sigma_{0}$ to zero. Ramoni and Anagnostou (2007a, b, 2008) improved this model by implementing the stress-point algorithm in accordance with the so-called "steady state method" of Nguyen Minh and Corbetta (1991), a numerical procedure for solving problems with constant conditions in the tunnelling direction by considering a reference frame, which is fixed to the advancing tunnel face. A recent description of the computational method (including its further development for poro-elastoplastic materials) and numerical comparisons with the step-by-step simulation of an advancing tunnel can be found in Anagnostou (2007) and Cantieni and Anagnostou (2009), respectively. The steady state method makes it possible to solve the advancing tunnel heading problem in one single computational step, i.e., without the need to simulate several sequences of excavation and support installation. As shown by Cantieni and Anagnostou (2009), the steady state method corresponds to the limit case of an excavation with zero round length. Therefore, it simulates TBM advance better than the commonly employed step-by-step method does, as the latter requires the arbitrary selection of a finite excavation round length, while TBM advance is actually a continuous process. For the commonly 
chosen, computationally manageable round length values of $s=1-2 \mathrm{~m}$, the step-by-step method leads to a considerable underestimation of the shield and lining loading (Cantieni and Anagnostou 2009). The choice of a smaller round length (e.g., $s=0.5 \mathrm{~m}$, cf. Sect. 5.3) improves accuracy but increases computer time. The computational economy and numerical stability of the steady state method made it possible to carry out a comprehensive parametric study and, based upon the numerical results of the study, to work out design nomograms concerning shield loading and the thrust force required to overcome friction in respect of the different TBM types (Ramoni and Anagnostou 2010a).

In all of these investigations, the ground behaviour was considered as being time-independent. Time effects were taken into account by Sterpi and Gioda (2007), who highlighted the fundamental effect of creep, as well as by Einstein and Bobet (1997) and Ramoni and Anagnostou (2007a, b), who studied the consolidation processes associated with the development and subsequent dissipation of excess pore pressures around the tunnel in a low-permeability water-bearing ground.

\section{Computational Model}

\subsection{Introduction}

The numerical investigations in this paper are based upon an axially symmetric model (Fig. 2). The condition of rotational symmetry presupposes that the tunnel is deepseated and crosses a hydrostatic, isotropic and uniform stress field. The ground is modelled as an isotropic, linear elastic, perfectly plastic material obeying the Mohr-Coulomb yield criterion and a non-associated flow rule.

Creep or consolidation processes have been disregarded. The gradual increase of ground pressure and of ground deformations in the longitudinal direction is therefore considered to be only due to the spatial stress redistribution that is associated with the progressive advance of the working face (Lombardi 1973). As in other works by the authors (see Sect. 2.3), the numerical calculations have been performed using the steady state method (Nguyen Minh and Corbetta 1991). For more information on the computational model and for a discussion of the underlying assumptions, the reader is referred to Ramoni and Anagnostou (2010a). In the present section, the paper focuses on the modelling of the interface between the ground and the shield or lining.

\subsection{Ground-Support Interface}

An accurate simulation of the two support elements "shield" and "tunnel support" must take into account, (1), their different installation points $(y=0$ and $y=L$ in Fig. 2, respectively) and, (2), that the shield and the tunnel support experience smaller displacements than the ground at any given point $y$ in the tunnel wall. This is due to the pre-deformation of the ground ahead of the tunnel face $u(0)$ and to the overcut $\Delta R$ which is usually present between the shield and the excavation boundary. In order to consider these aspects, a mixed and non-uniform boundary condition is introduced for the tunnel wall, which in a general form reads as follows:

$p(y)=\left\{\begin{array}{l}f_{\mathrm{s}}(u(y)) \text { if } 0 \leq y \leq L \\ f_{1}(u(y)) \text { if } y>L\end{array}\right.$,

where $p(y)$ is the ground pressure developing upon the shield or the lining; $u(y)$ is the radial displacement of the ground at the tunnel boundary; $L$ denotes the shield length; and the functions $f_{\mathrm{s}}$ and $f_{1}$ describe the displacementdependency of the resistance of the shield (Sect. 3.3) and of the tunnel support (Sect. 3.4), respectively.

\subsection{Shield}

The function $f_{\mathrm{s}}$ takes account of the fact that the ground starts to exert a load upon the shield only after closing the radial gap around the shield, i.e., after experiencing an additional deformation of $\Delta R$ behind the face, where $\Delta R$
Fig. 2 Problem layout indicating the different installation points of the shield and of the lining

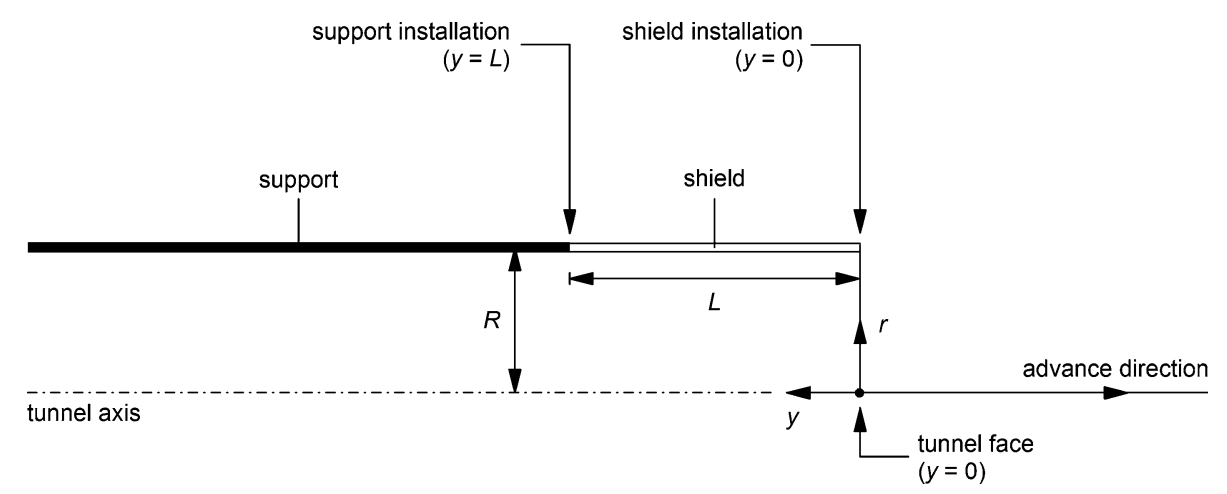


denotes the size of the radial gap (Fig. 3a). After the closure of the gap, assuming that the shield is able to bear the load without being overstressed, there is a linear dependence between the developing ground pressure $p$ and the shield stiffness $K_{\mathrm{s}}$.

Shields may have a "conical" shape. This so-called "conicity" of the shield is realised with a stepwise reduction of the shield diameter (Herrenknecht 2010). In the computational model, this can be taken into account defining a variable radial gap size $\Delta R(y)$. For example, if the conicity of the shield is realized in two steps (Fig. 4), the non-uniform mixed boundary conditions of Eq. 1 reads, in a general way, as follows: shown later in the Sects. 4.3 and 6.3, a detailed simulation of the behaviour of the tunnel support is also important for analyzing its interaction with the shield. Specifically, a rigid support that is installed close to the shield tail facilitates load transfer in the longitudinal direction, thus reducing the ground pressure acting upon the shield. On the other hand, the tunnel support has to bear a higher load in this case.

\subsection{Simplified Model}

As a simplified model for estimating shield loading, a uniform boundary condition (defined by the function $f_{\mathrm{s}}$ ) can

$p(y)= \begin{cases}0 & \text { if } 0 \leq y \leq L \text { and } u(y)-u(0) \leq \Delta R(y) \\ K_{\mathrm{s}}(u(y)-u(0)-\Delta R(y)) & \text { if } 0 \leq y \leq L \text { and } u(y)-u(0)>\Delta R(y), \\ K_{\mathrm{l}}(u(y)-u(L)) & \text { if } y>L\end{cases}$

where

$\Delta R(y)=\left\{\begin{array}{l}\Delta R_{1} \text { if } 0 \leq y \leq L_{1} \\ \Delta R_{2} \text { if } L_{1}<y \leq L_{2} \\ \Delta R_{3} \text { if } L_{2}<y \leq L_{3}\end{array}\right.$

A numerical example illustrating the effect of the conicity of the shield will be discussed in Sect. 4.3.

\subsection{Tunnel Support}

The boundary condition $f_{1}$ makes it possible to simulate each kind of tunnel support. Figure 3 b shows the boundary condition applied for stiff supports (for example, a shotcrete layer or a segmental lining being immediately backfilled). Note that the assumption of a constant lining stiffness $K_{1}$ presupposes that the lining is not overstressed. On the other hand, Fig. 3c shows, in general terms, a definition of the boundary condition that would simulate the non-linear behaviour of a yielding support (for details see the application example described in Sect. 6). As be applied to the entire tunnel boundary. In this case, the shield and the tunnel support are modelled as a unique body having the same stiffness and the same radial gap size $\Delta R$. This simplification has been made, e.g., by Ramoni and Anagnostou (2006) and Sterpi and Gioda (2007) and allows a faster investigation to be made of the effect of the shield length $L$ on the thrust force that is required to overcome shield skin friction because, in cases such as this, it is sufficient to integrate the function $p(y)$ over a tunnel sector $0 \leq y \leq L$ of arbitrary length $L$ without needing to carry out an individual numerical computation for each shield length. There are, however, several reasons for using the non-uniform boundary condition of Eq. 1.

The simplified model disregards the fact that the installation of the tunnel support occurs later than that of the shield (Fig. 2) and does not account for the radial unloading of the excavation boundary at the lining installation point. This leads to an overestimation of the lining loading. This is important not only with respect to the design of the lining, but also for the loading of the shield.
Fig. 3 Boundary condition at the tunnel boundary for the simulation of: a shield, b stiff supports, c yielding supports

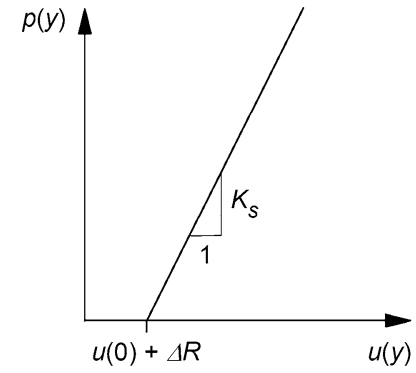

(a)

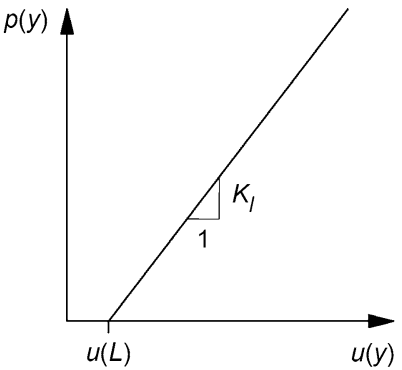

(b)

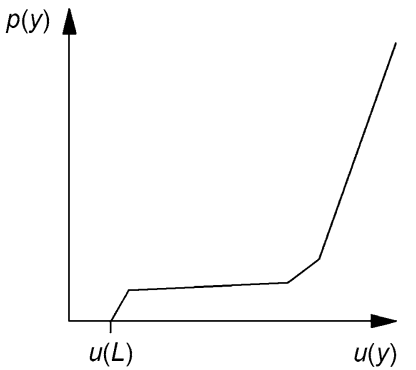

(c) 
Fig. 4 Stepwise reduction of the shield diameter (conicity)

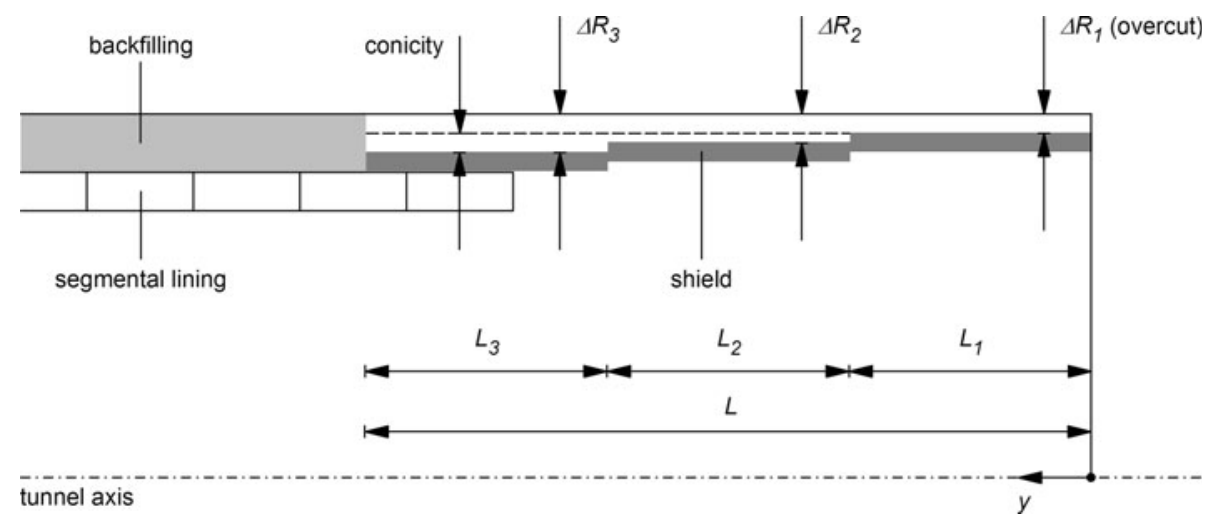

Table 1 Assumed parameter values

In fact, the overestimation of the support pressure exerted by the lining behind the shield leads (due to the longitudinal arch action in the ground around the shield) to an underestimation of the shield loading and, consequently, of the thrust force that is required in order to overcome shield skin friction. (Section 4.3 analyzes quantitatively this effect by means of a numerical example.)

Furthermore, the simplified boundary condition presupposes that the gap size $\Delta R$ is constant along the shield and the lining and, consequently, it is not able to map neither shield conicity nor the perfect contact between lining and ground existing in some cases right from the start (for example, in the case of a gripper TBM with support by shotcrete or of a shielded TBM with annulus grouting taking place simultaneously with TBM advance via the shield tail).

\section{Basic Aspects of the Interaction between Shield, Ground and Tunnel Support}

The interaction between the shield, the ground and the tunnel support will be analyzed by means of numerical examples for the hypothetical case of a $400 \mathrm{~m}$ deep tunnel with a boring diameter of $10 \mathrm{~m}$. The tunnel is excavated by a TBM with a $10 \mathrm{~m}$ long single shield. The support consists of a $30 \mathrm{~cm}$ thick segmental lining being immediately backfilled. The material constants are specified in Table 1 (Set 1).

The ground pressure developing upon the shield is of paramount importance both for the structural design of the machine and for the frictional resistance to be overcome when advancing the TBM. As the ground starts to exert pressure upon the shield only after a certain amount of deformation has occurred, this section starts with a discussion of the convergences and pressures developing along the tunnel (Sect. 4.1) and shows how much the geometrical parameters of the shield influence the degree of overstressing and the stress history of the ground (Sect. 4.2) as well as the thrust force required in order to

\begin{tabular}{llllll}
\hline \multicolumn{5}{l}{ Set (figures) } \\
\cline { 2 - 6 } & $1(5-10)$ & $2(11)$ & $3(12)$ & $4(14-15)$ & $5(18)$ \\
\hline$R(\mathrm{~m})$ & 5.00 & 5.00 & 2.50 & 2.50 & 4.75 \\
$\Delta R(\mathrm{~cm})$ & $0-20$ & 5 & $3 / 6 / 9 / 12$ & 3 & 12 \\
$L(\mathrm{~m})$ & $6-12 / \infty$ & $0-12$ & $10 / 12$ & 12 & 5 \\
$K_{\mathrm{S}}(\mathrm{MPa} / \mathrm{m})$ & 1,008 & 1,008 & 2,688 & 2,688 & 558 \\
$K_{1}(\mathrm{MPa} / \mathrm{m})$ & 360 & $0 / \infty$ & 2,688 & 2,688 & Variable \\
$\sigma_{0}(\mathrm{MPa})$ & 10 & 10 & 3 & 3 & 40 \\
$E(\mathrm{MPa})$ & 1,000 & 2,000 & $200-1,000$ & $2,000^{\mathrm{a}} 400^{\mathrm{b}}$ & 3,235 \\
$v(-)$ & 0.25 & 0.25 & 0.20 & 0.20 & 0.30 \\
$f_{\mathrm{c}}(\mathrm{MPa})$ & 3.0 & 4.5 & - & - & 5.5 \\
$c(\mathrm{kPa})$ & - & - & $500-400$ & $200^{\mathrm{b}}$ & - \\
$\varphi\left(^{\circ}\right)$ & 25 & 25 & 20 & $20^{\mathrm{b}}$ & 35 \\
$\psi\left({ }^{\circ}\right)$ & 5 & 5 & 1 & $1^{\mathrm{b}}$ & 5 \\
$\mu(-)$ & $0.15 / 0.25 /$ & 0.45 & $0.25 / 0.50$ & 0.50 & 0.30 \\
& $0.30 / 0.45$ & & & & \\
$F_{\mathrm{i}}(\mathrm{MN})$ & 150 & - & $30 / 60$ & 30 & 27.5 \\
$F_{\mathrm{b}}(\mathrm{MN})$ & $0 / 18$ & 0 & 0 & 0 & 17 \\
$s(\mathrm{~m})$ & - & - & - & $0.5 / 1.0$ & - \\
\hline
\end{tabular}

a Competent rock

b Weak zone

overcome friction (Sect. 4.3). Specifically, this section will show that the ground at the excavation boundary experiences several unloading and reloading cycles and that a stepwise reduction of the shield diameter is very favourable with respect to the ground pressure. Furthermore, Sect. 4.3 discusses quantitatively the simplified model for the shieldground interface mentioned in Sect. 3.5 and shows how important it is to take into account as realistically as possible the geometrical characteristics and the installation sequence of the shield and the tunnel support. In this respect, it is important to note that the installation point and the stiffness of the tunnel support are essential not only for its loading but also for the pressure developing upon the shield (Sect. 4.4). 


\subsection{Shield-Ground Interaction}

Figure 5a shows the radial displacement $u$ of the ground at the tunnel boundary for three values of the size $\Delta R$ of the radial gap between shield and ground. The latter determines the amount of convergence that can occur freely. Figure $5 \mathrm{~b}$ shows the convergence $u-u(0)$ of the bored profile, i.e., the total radial displacement $u$ less the so-called "pre-deformation" $u(0)$ that occurs ahead of the tunnel face. In the case of a normal overcutting $(\Delta R=5 \mathrm{~cm})$ the ground closes the gap near to the face (at point A, Fig. 5b). A larger gap $(\Delta R=10 \mathrm{~cm})$ remains open for a longer interval (up to point B, Fig. 5b). After closing the gap, the ground starts to load the shield.
Figure 5c shows the distribution of the ground pressure $p$ acting upon the shield and the lining. The ground pressure increases with the distance from the tunnel face as the stabilizing effect of the core ahead of the face becomes less pronounced. The load concentration at the end of the shield can be traced back to the complete unloading of the tunnel boundary at the installation point of the lining.

As expected, the ground pressure $p$ decreases (both for the shield and the lining) when a larger overboring is provided. In the case of a very large overboring of $\Delta R=15 \mathrm{~cm}$ the gap between ground and shield would not close at all in this numerical example and the shield would remain unloaded. It should be noted, however, that overboring technology is not yet well developed and, as shown
Fig. 5 Results of numerical computations for a $10 \mathrm{~m}$ long shield and for an overboring $\Delta R$ of 5,10 or $15 \mathrm{~cm}$ : a radial displacement $u$ of the ground at the tunnel boundary,

b convergence $u-u(0)$ of the bored profile, c ground pressure $p$ acting upon the shield and the lining; other parameters according to Table 1, Set 1
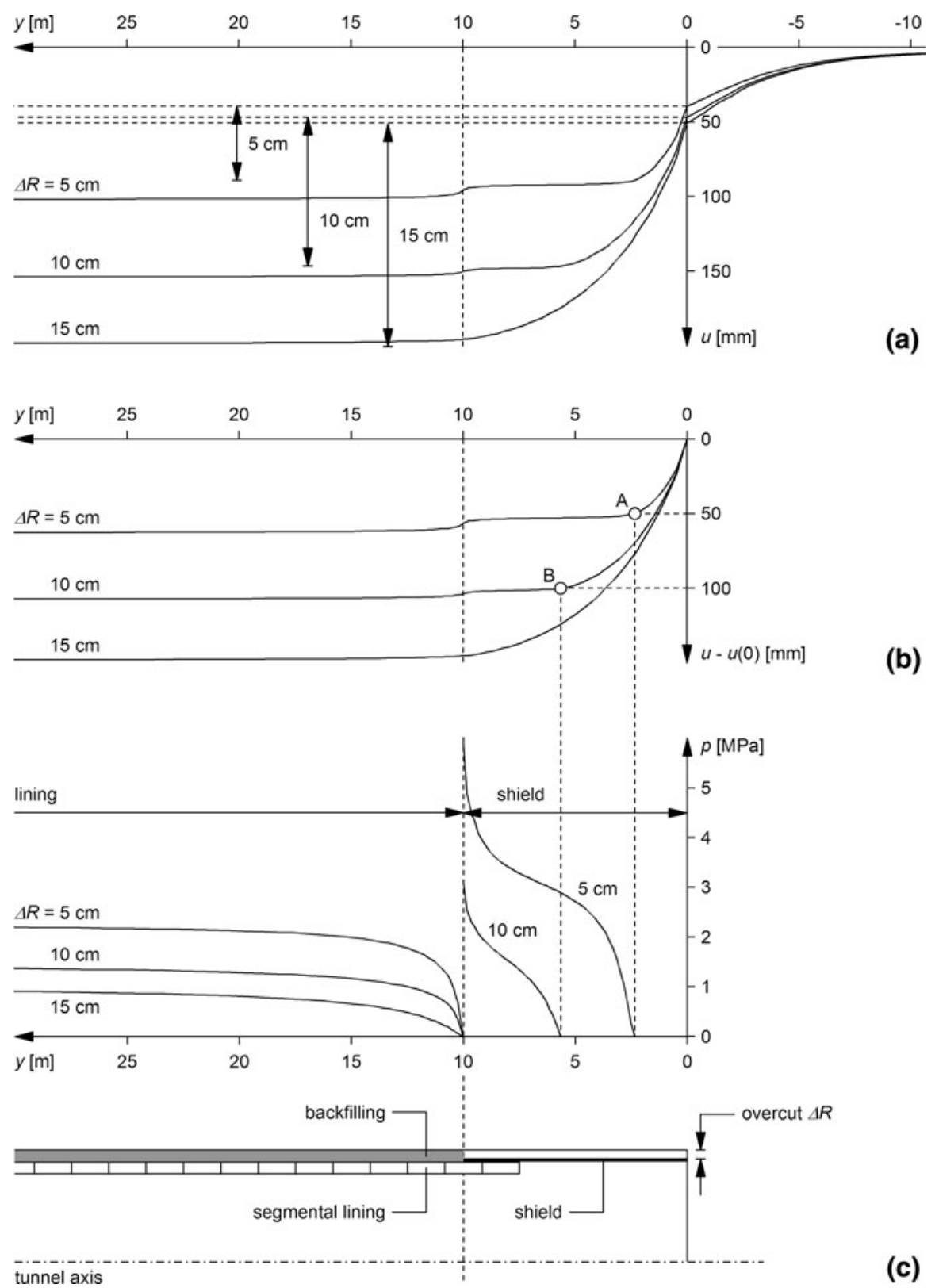

(c) 
from tunnelling experience, may be of limited reliability (ITA 2003; Ramoni and Anagnostou 2010b). The feasibility and the reliability of a large overboring have to be checked carefully particularly for hard rocks because very high loads act upon the extended gauge cutters in this case and may endanger their structural safety.

\subsection{Overstressing and Stress History of the Ground}

On the one hand, providing a larger overboring leads to a lower shield loading and therefore to a lower frictional resistance during shield advance. On the other hand, a larger radial gap allows a larger deformation $u$ to occur and, therefore, there is a more extended zone of overstressed ground around the tunnel (Fig. 6). In this numerical example, the thickness of the plastic zone increases from 2.8 to $5.5 \mathrm{~m}$ practically linearly with the size $\Delta R$ of the radial gap $(\Delta R=5-15 \mathrm{~cm})$. In a ground exhibiting brittle behaviour, the deformations and the overstressing may enhance loosening and softening of the ground, thus favouring gravity-driven instabilities. This may lead to problems with the installation of the tunnel support (gripper TBMs) or the backfilling of the segmental lining (shielded TBMs). The issue of loosening and softening is particularly important for the design of a yielding support, because both strength loss and major loosening call for a higher yield pressure in the support system (Anagnostou and Cantieni 2007). An example will be discussed in Sect. 6.3 of the present paper.

In the so-called "past-yield zone" (Fig. 6), the deformations of the ground are partially irreversible but its stress state is located within the elastic domain. The ground has experienced plastic yielding in the past, but has become elastic again. The reason for this so-called "elastic recompression" (Gärber 2003) is the development of a radial pressure from the lining with increasing distance from the tunnel face. Figure 7 provides a complete picture of the stress history of the ground. With the approaching tunnel excavation, the axial stress $\sigma_{\mathrm{yy}}$ decreases ahead of the tunnel face, while a stress concentration occurs in the radial and the tangential directions (Fig. 7a). Near the tunnel face, the stress deviator becomes so large that the core yields, plastic deformations start to develop and, due to Mohr-Coulomb yield condition, the radial and the tangential stresses $\sigma_{\text {rr }}$ and $\sigma_{\mathrm{tt}}$ decrease together with the axial stress $\sigma_{\mathrm{yy}}$. In the principal stress diagram of Fig. 7b, the onset of plastic yielding is indicated by the point $\mathrm{C}$. At the tunnel face, the radial stress $\sigma_{\text {rr }}$ becomes equal to zero and the tunnel boundary remains unsupported as long as the gap between shield and bored profile is open. Because of the Mohr-Coulomb yield criterion, the maximum principal stress over this unsupported span becomes equal to the uniaxial compressive strength $f_{\mathrm{c}}$. (The stress state over the unsupported span is indicated by the point $\mathrm{D}$ in the principal stress diagram of Fig. 7b.)

At a certain distance behind the face, the converging ground closes the gap and the shield starts to develop a radial support pressure $\sigma_{\text {rr }}$ upon the tunnel boundary with the consequence that the ground is able to sustain a higher stress level and the stress state returns to the elastic domain (Fig. 7b, stress path DE). As can be seen in Fig. 7a, the ground experiences two unloading (to $\sigma_{\mathrm{rr}}=0$ ) and reloading cycles, the first being near to the tunnel face until the ground closes the gap (Fig. 7b, stress path ABCDE) and the second at the end of the shield, where lining installation takes place (stress path EFGH). As can be seen from Fig. 8, which shows the radial stress $p$ at the excavation boundary for different shield geometries, unloading-reloading cycles occur several times if the shield has a stepwise decreasing diameter ("conical shield", cf. Sect. 3.3).

It is also interesting to note that the wider the radial gap, the more time it takes for the ground to close the gap, leading to a later occurrence of elastic re-compression and a bigger plastic zone in the longitudinal direction (Fig. 6). Therefore, for example, if $\Delta R=15 \mathrm{~cm}$ the gap remains open over the entire shield length $L$ (which can be seen as a free span between the tunnel face and the lining) and the plastic zone extends up to the end of the shield ( $y=L=10$ m, Fig. 6c).

\subsection{Thrust Force}

The thrust force $F_{\mathrm{r}}$ required to overcome shield skin friction can be calculated easily by integrating the ground pressure $p$ over the shield surface and multiplying the integral by the skin friction coefficient $\mu$. Figure 9 a shows the effect of radial gap size $\Delta R$ on required thrust force $F_{\mathrm{r}}$ for two operational stages ("ongoing excavation" and
Fig. 6 Plastic zone for a $10 \mathrm{~m}$ long shield and for an overboring $\Delta R$ of: a $5 \mathrm{~cm}$, b $10 \mathrm{~cm}$, c $15 \mathrm{~cm}$; other parameters according to Table 1, Set 1

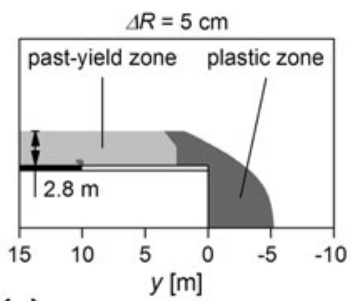

(a)

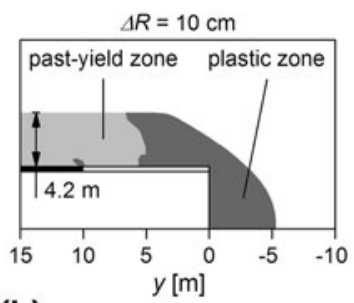

(b)

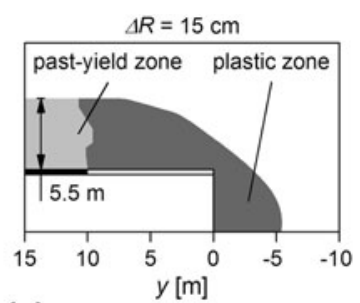

(c) 
Fig. 7 Results of numerical computations for a normal overcut of $\Delta R=5 \mathrm{~cm}$ and a shield length of $L=10 \mathrm{~m}$ : a history of the radial $\left(\sigma_{\mathrm{rr}}\right)$, tangential $\left(\sigma_{\mathrm{tt}}\right)$, axial $\left(\sigma_{\mathrm{yy}}\right)$ and shear stress $\left(\sigma_{\mathrm{ry}}\right)$ along the tunnel boundary, b principal stress paths along the tunnel boundary; other parameters according to Table 1, Set 1
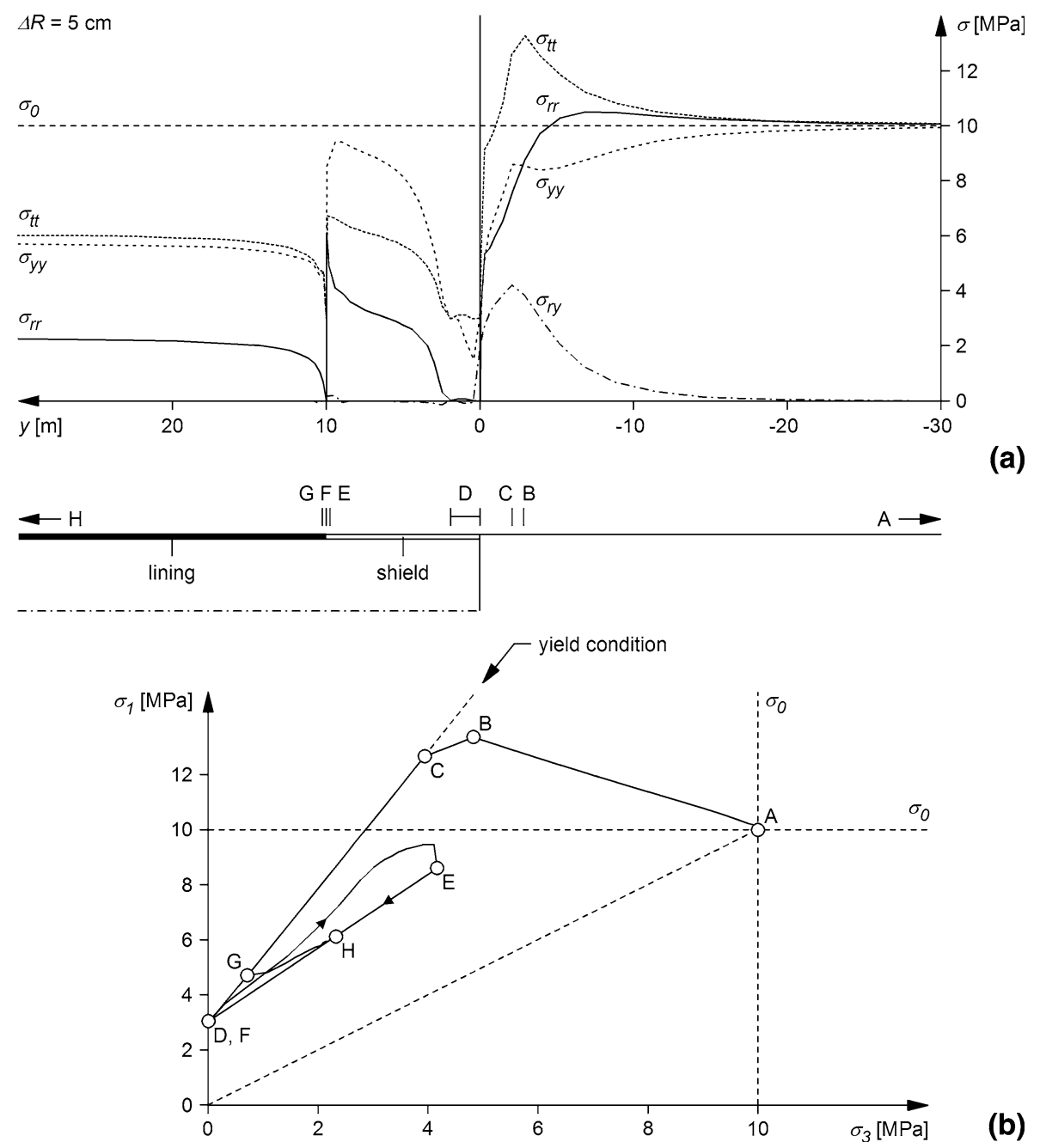

(b)

Fig. 8 Ground pressure $p$ acting upon the shield and the lining for three different shield geometries having the same average radial gap size (shield length $L=10 \mathrm{~m}$, radial gap size $\Delta R=4-6 \mathrm{~cm}$; other parameters according to Table 1, Set 1)
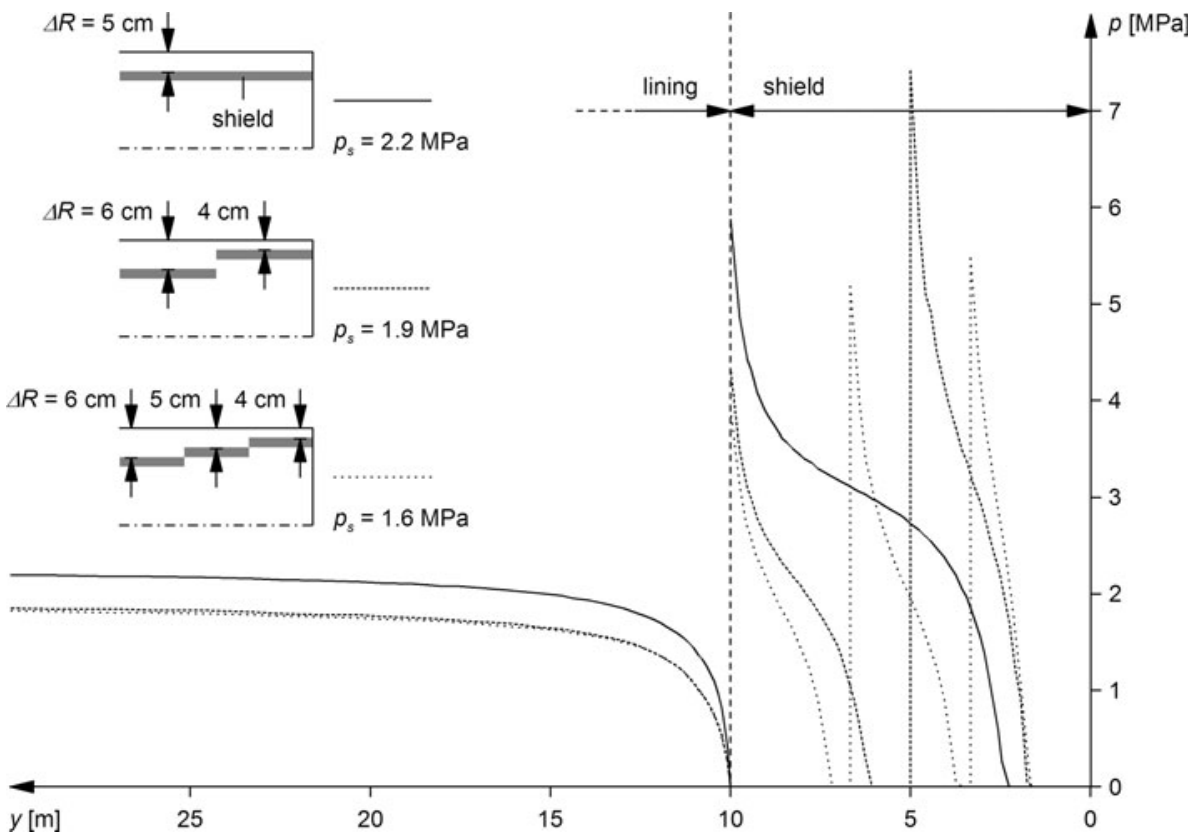
"restart after a standstill"). During ongoing excavation, the TBM has to overcome sliding instead of static friction, but, on the other hand, an additional thrust force $F_{\mathrm{b}}$ is needed for the boring process $\left(F_{\mathrm{b}}\right.$ was taken to $18 \mathrm{MN}$ in this example). Following Gehring (1996), the skin friction coefficient was taken to be $\mu=0.15-0.30$ for sliding friction and $\mu=0.25-0.45$ for static friction, where the lower friction coefficient values aim to illustrate the positive effects of lubrication of the shield extrados, e.g., by bentonite. The line marked by $F_{\mathrm{i}}$ denotes a high, but still feasible thrust force of $150 \mathrm{MN}$.

Figure $9 \mathrm{~b}$ shows the required thrust force $F_{\mathrm{r}}$ as a function of the shield length $L$ for the two operational stages and an overcut of $\Delta R=5-15 \mathrm{~cm}$. The diagram illustrates the positive effect of a shorter shield. It has to be noted that the dependency of thrust force on the shield length is in general non-linear.

As shown in a condensed form by Fig. 9, the required thrust force $F_{\mathrm{r}}$ depends strongly on the shield length $L$, on the skin friction coefficient $\mu$ and on the overcut $\Delta R$. Another important TBM design parameter is the so-called "conicity" of the shield, i.e., the variation $\Delta R(y)$ of the radial gap size along the shield (cf. Sect. 3.3). Figure 8 shows the ground pressure $p$ acting upon the shield and the lining for three different shield geometries having the same average radial gap size of $\Delta R=5 \mathrm{~cm}$. The positive effect of a stepwise construction of the shield becomes evident when comparing the average ground pressure $p_{\mathrm{s}}$ (which governs the required thrust force) acting upon the shield. It decreases by 16 or $28 \%$, respectively, where there are two or three steps in the construction of the shield (Fig. 8). A wide gap is more important for the rear part of the shield because the convergence of the ground increases with the distance behind the face.

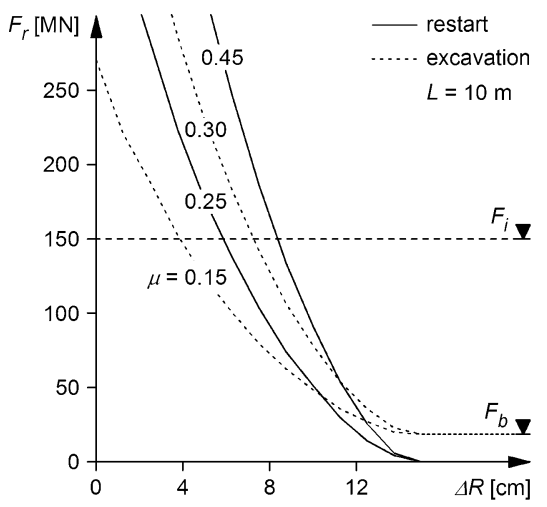

(a)

Fig. 9 Required thrust force $F_{\mathrm{r}}$ during ongoing excavation (thrust force for the boring process $F_{\mathrm{b}}=18 \mathrm{MN}$ ) and for the restart after a standstill with (skin friction coefficient $\mu=0.15$ or 0.25 , respectively) or without (skin friction coefficient $\mu=0.30$ or 0.45 ,
As mentioned in Sect. 3.5, the computational model can be simplified by modelling the shield and the lining as a single infinitely long cylindrical body of constant stiffness and radial gap size. Figure 10a compares the longitudinal distribution of the ground pressure $p$ of the simplified model with a pressure distribution based on the more accurate model discussed in the previous sections (for a $10 \mathrm{~m}$ long shield). The simplified computational model overestimates the ground pressure developing upon the lining (by $56 \%$ in the final state developing far behind the face) and, consequently, the supporting effect of the lining in the area immediately behind the shield (the diagonally dashed region in Fig. 10a). Due to the load transfer in the longitudinal direction, this leads to a lower shield loading (the vertically dashed region in Fig. 10a), thereby underestimating the thrust force required to overcome friction. Figure $10 \mathrm{~b}$ shows the thrust force $F_{\mathrm{r}}$ required to restart TBM advance after a standstill as a function of the shield length $L$ in the simplified model and based upon the more accurate model with the non-uniform boundary condition (Eq. 1). The simplified model underestimates the thrust force by about $40 \mathrm{MN}$ in this example. It is therefore important to model the characteristics and the installation point of the tunnel support as accurately as possible, not only from the perspective of structural assessment but also with respect to the design of the TBM.

\subsection{Shield-Support Interaction}

The installation of a stiff support close to the shield reduces the shield loading and the thrust force requirement because it improves load transfer in the longitudinal direction. The stiffer the lining and the shorter its distance from the face,

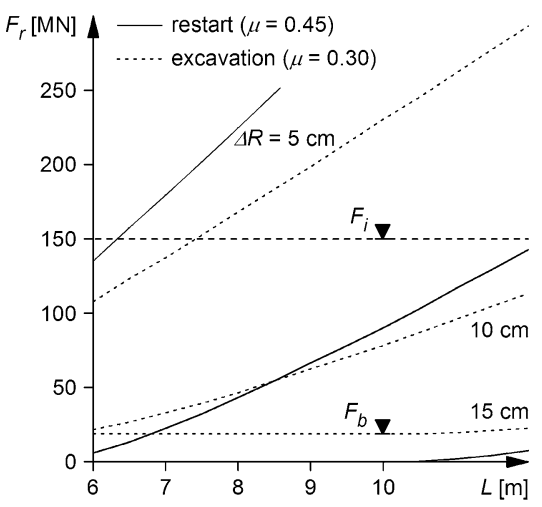

(b)

respectively) lubrication of the shield extrados: $\mathbf{a}$ as a function of the overboring $\Delta R$ for a $10 \mathrm{~m}$ long shield, $\mathbf{b}$ as a function of the shield length $L$ for an overboring $\Delta R$ of 5,10 or $15 \mathrm{~cm}$; other parameters according to Table 1 , Set 1 
Fig. 10 Distribution of the ground pressure $p$ acting upon the shield and the lining (a) and required thrust force $F_{\mathrm{r}}$ as a function of the shield length $L$ (b) based upon the simplified model as well as for a model employing a non-uniform boundary condition (radial gap size $\Delta R=5 \mathrm{~cm}$, skin friction coefficient $\mu=0.45$; other parameters according to Table 1, Set 1)

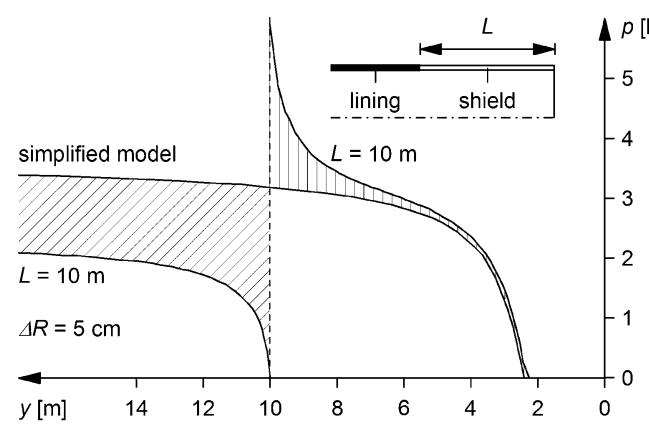

(a)

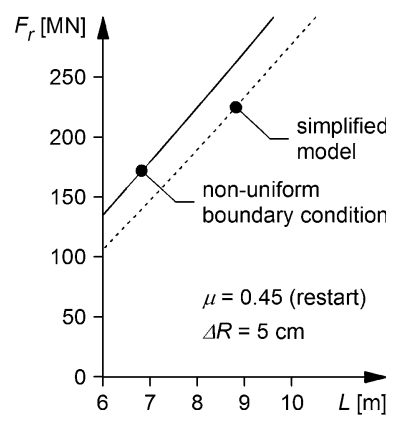

(b) the more pronounced will be the longitudinal arching effect and the bigger will be the reduction of the shield load.

The upper part of Fig. 11a illustrates this effect by presenting the thrust force $F_{\mathrm{r}}$ (required for restarting TBM advance after a standstill) as a function of the shield length $L$ for two borderline cases with respect to support stiffness: a rigid support $\left(K_{1}=\infty\right)$ and an unsupported tunnel $\left(K_{1}=0\right)$. As expected, the unloading effect is more pronounced for short shields. A stiff support that is installed close to the face is favourable with respect to the shield but, nevertheless, attracts a higher ground load. In fact, for short shields (where the longitudinal arching effect is particularly pronounced) the final ground pressure $p$ developing upon the rigid support $\left(K_{1}=\infty\right)$ reaches values that cannot be sustained by the usual linings (Fig. 11a, lower part). As expected, the load of the tunnel support $p$ decreases with increasing shield length $L$, i.e., with decreasing arching effect.

It should be noted that the case of an unsupported tunnel is not only theoretically possible. In fact, in shield tunnelling through rock, backfilling of the segmental lining by pea gravel is carried-out at a certain distance behind the shield with the consequence that the rock behind the shield actually remains unsupported (Fig. 11b). There is no unloading effect in this case, of course (point A in Fig. 11a). Shield load reduction (point $B$ in Fig. 11a) via longitudinal arching between the face and the segmental lining presupposes annulus grouting simultaneously with TBM advance via the
Fig. 11 a Required thrust force $F_{\mathrm{r}}$ and final ground pressure $p$ acting upon the lining as a function of the shield length $L$ for a rigid support $\left(K_{1}=\infty\right)$ as well as for an unsupported tunnel $\left(K_{1}=0\right)$; radial gap size $\Delta R=5 \mathrm{~cm}$, skin friction coefficient $\mu=0.45$; other parameters according to Table 1, Set 2; b single shielded TBM in rock with delayed backfilling of the segmental lining (case A of a); c single shielded TBM with annulus grouting via the shield tail (case B of a)

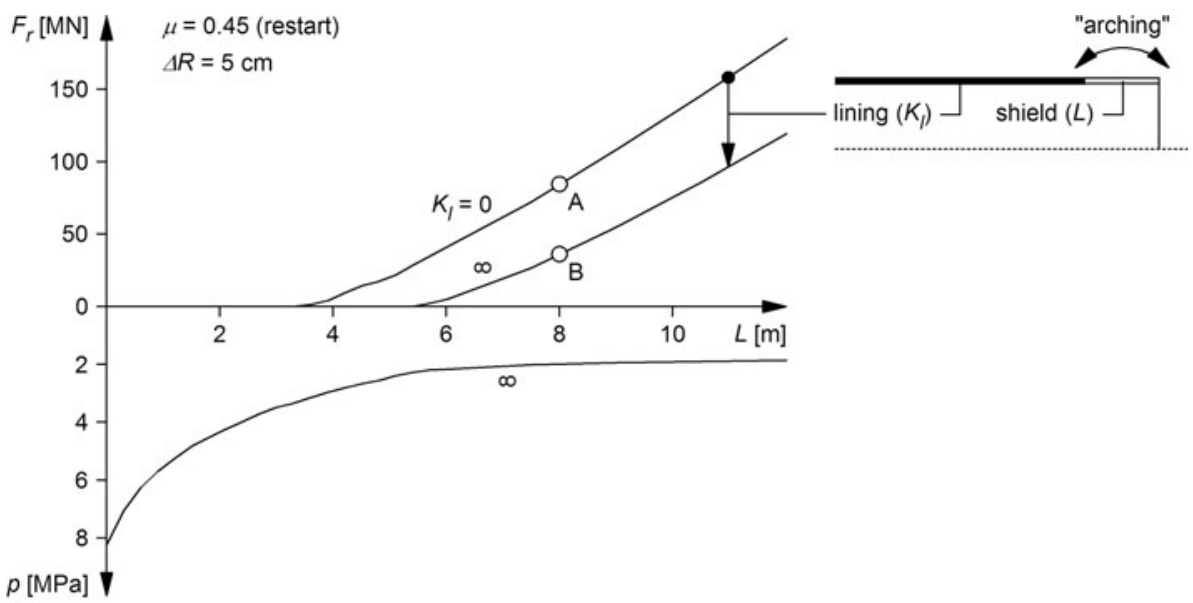

(a)

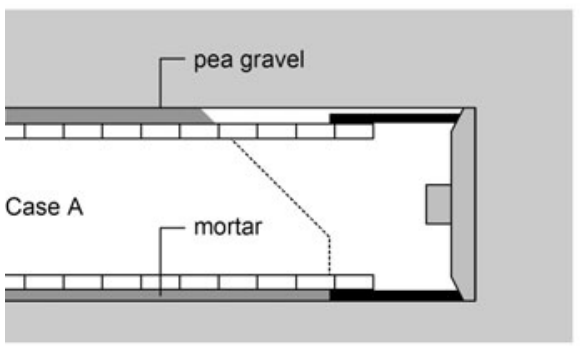

(b)

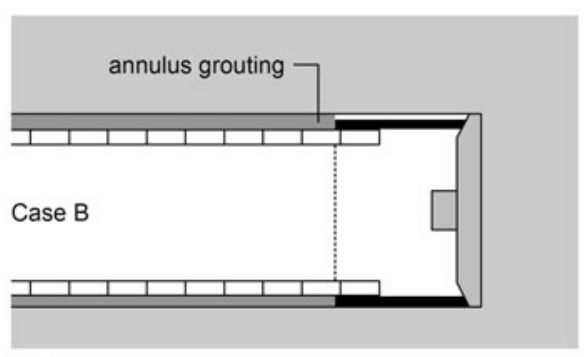

(c) 
shield tail (Fig. 11c). The peculiarities of segmental lining installation have been analyzed by Lavdas (2010).

\section{An Example of a Single Shielded TBM}

\subsection{Introduction}

The first application example concerns the $11.8 \mathrm{~km}$ long Uluabat Tunnel in Turkey (about $100 \mathrm{~km}$ south of Istanbul). A $12 \mathrm{~m}$ long single shielded TBM with a boring diameter of $5.05 \mathrm{~m}$ and an installed thrust force of about $30 \mathrm{MN}$ started work in 2006. The overcut $\Delta R$ was $3 \mathrm{~cm}$ at the front part of the shield and increased to $4 \mathrm{~cm}$ at the shield tail. The ground is of Triassic origin and consists of a claystone matrix containing $1-50 \mathrm{~cm}$ big sandstone lenses. The claystone fraction amounts to about $80 \%$. The claystones are intensively sheared, have several slickensides and disintegrate quickly under the action of water. Laboratory results revealed an angle of internal friction of about $\varphi=20^{\circ}$, strongly variable cohesion values $(c=50-400 \mathrm{kPa})$ and a Young's modulus of $E=200-1000 \mathrm{MPa}$. During the first $3 \mathrm{~km}$ of TBM operation, squeezing caused jamming of the shield on several occasions although the depth of cover was rather moderate (about $120 \mathrm{~m}$, i.e., an estimated initial stress of $\sigma_{0}=3 \mathrm{MPa}$ ). The available monitoring results were sparse, but indicated a large variability in squeezing intensity with maximum deformation rates of up to $60 \mathrm{~mm} / \mathrm{h}$.

A comprehensive parametric study was carried out in order to gain a better understanding of the observed phenomena, analyze the factors influencing the jamming of the TBM and evaluate the effectiveness of possible TBM improvements (Kovári and Ramoni 2008; Ramoni and
Anagnostou 2008). Because of the variability of the squeezing phenomena, attention was paid to the specific situation prevailing in certain critical zones. The following sections outline the most important results.

\subsection{Investigations on TBM Optimization}

The numerical investigations were carried out based on an axially symmetric model with the simplified boundary condition of Sect. 3.5 and a constant overcut $\Delta R$ along the shield. The calculations disregarded a possible timedependency of the ground behaviour-a reasonable assumption considering the high convergence rates observed in situ. Furthermore, because of the low strength of the ground, the thrust force calculations neglected the boring thrust force. The skin friction coefficient was taken to $\mu=0.50$ after Gehring (1996). This value is relevant for the static friction conditions prevailing when attempting to restart excavation after a stop for the installation of the segmental lining.

For a given depth of cover and for given TBM parameters, a critical range of rock mass parameters can be determined beyond which the required thrust force is higher than the installed one, thus indicating that shield jamming may occur. In the present case, the critical range was defined in terms of the Young's modulus $E$ and of the cohesion $c$ of the rock mass (all other ground parameters being kept constant). The reason for this choice was the large uncertainty concerning these two parameters in combination with the great sensitivity of the ground response with respect to their variations.

Figure 12a shows the critical ground conditions for a depth of cover of $H=120 \mathrm{~m}$ and an overcut $\Delta R$ of 3,6 or
Fig. 12 a Critical ground conditions for an installed thrust force of $F_{\mathrm{i}}=30 \mathrm{MN}$ (radial gap size $\Delta R=3,6$ or $9 \mathrm{~cm}$, shield length $L=12 \mathrm{~m}$, skin friction coefficient $\mu=0.50$, depth of cover $H=120 \mathrm{~m}$, safety factor for the required thrust force $S F=2.0)$, b effect of a combination of several technical improvements (installed thrust force $F_{\mathrm{i}}=30 \rightarrow 60 \mathrm{MN}$, radial gap size $\Delta R=6 \rightarrow 12 \mathrm{~cm}$, shield length $L=12 \rightarrow 10 \mathrm{~m}$, skin friction coefficient $\mu=0.50 \rightarrow 0.25$, depth of cover $H=120$ or $240 \mathrm{~m}$, safety factor for the required thrust force $S F=2.0$ ); other parameters according to Table 1, Set 3

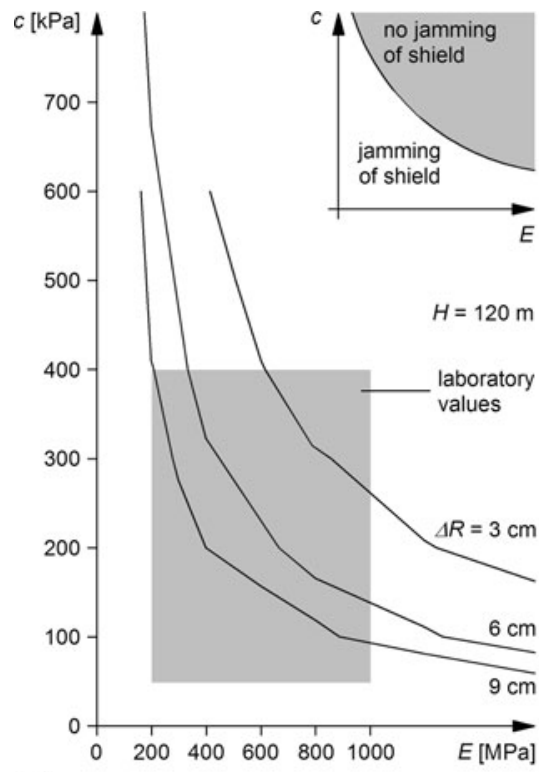

(a)

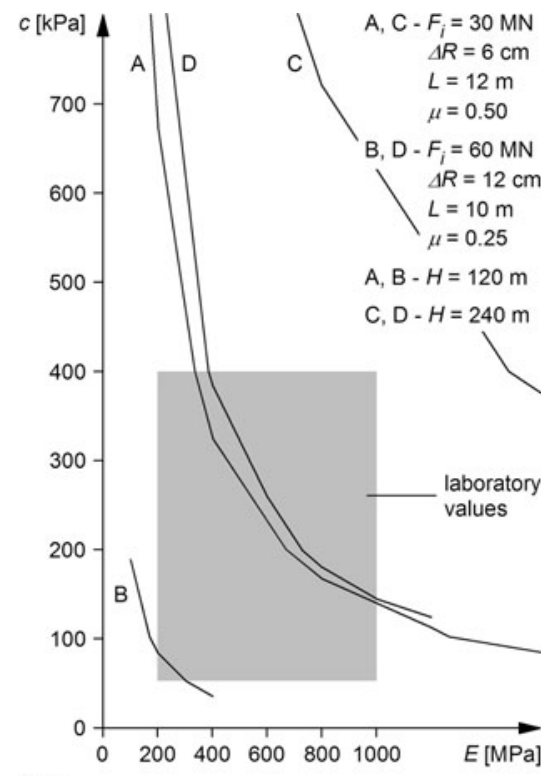

(b) 
$9 \mathrm{~cm}$ (the 6-9 $\mathrm{cm}$ applies to the case of an increased overcut). The points of each curve (hereafter referred to as "critical curve") fulfil the condition that the required thrust force (for the specific value of $\Delta R$ ) is equal to the installed force. The lower the Young's modulus $E$, the higher the cohesion $c$ must be in order that the average ground pressure acting upon the shield remains equal to a given value. Value-pairs $(c, E)$ above a certain curve characterize subcritical ground conditions (i.e., the installed thrust force is sufficient for overcoming the frictional resistance of the ground). On the other hand, the region below the critical curve indicates ground conditions that may trap the TBM. The grey box shows the actual range of the two ground parameters based upon the results of laboratory tests. By considering the position of the critical curve relative to this box, an optical assessment can be made of TBM operating conditions. The fact that the critical curves diagonally cross the box representing the laboratory values points to a prediction uncertainty and agrees with the variability experienced during the TBM drive: depending on the variation of the ground conditions the shield may or may not be jammed.

In order to reduce the risk of major delays in the completion of the project, the option of an additional TBM drive from the other portal of the tunnel was investigated (but finally rejected for contractual reasons). The second TBM would cross the same formation, where the first TBM experienced difficulties, but under an even higher overburden (up to $240 \mathrm{~m}$ in the deepest portion of the alignment). A main goal of the investigations was, therefore, the optimization of the second TBM in order to cope with squeezing ground. Figure $12 \mathrm{~b}$ shows the critical curves for a depth of cover of $120 \mathrm{~m}$ (curves A and B) or $240 \mathrm{~m}$ (curves $\mathrm{C}$ and D). The critical curves for the first machine are denoted by $\mathrm{A}$ and $\mathrm{C}$, while the curves $\mathrm{B}$ and $\mathrm{D}$ apply to a new machine implementing a series of technical improvements: a higher thrust force $F_{\mathrm{i}}$ (60 instead of 30 $\mathrm{MN}$ ), a $2 \mathrm{~m}$ shorter shield length $L$, a bigger overboring $\Delta R$ and reduced skin friction (achieved by lubrication of the shield extrados). The combination of all these measures would shift the critical curve from curve A to curve B in the bottom-left corner of the diagram and this means that an improved TBM would be able to cope with adverse conditions such as those encountered by the first TBM at a depth of cover of $H=120 \mathrm{~m}$. However, the possibility of shield jamming would persist in the deepest portion of the alignment $(H=240 \mathrm{~m})$. According to curve D of Fig. 12b, the improved TBM would perform at a depth of $240 \mathrm{~m}$ similarly to the current TBM at a depth of $120 \mathrm{~m}$ (curve A), while operation of the current TBM at the maximum depth would be possible only in the case of considerable improvements to ground strength and stiffness (curve C).

\subsection{Effect of Short Weaker Zones}

The numerical computations presented in the last section were based on the assumption of homogeneous ground in the longitudinal direction. During the TBM drive in Uluabat, however, the ground behaviour, as reflected by the thrust force needed in order to keep the TBM advancing, changed within short intervals, thus indicating a succession of weak zones with stretches of more competent ground. According to past research on the mechanics of deformation in short geological fault zones, the adjacent competent rock also has a stabilizing effect with respect to the fault zone (Cantieni and Anagnostou 2007; Kovári and Anagnostou 1995). When crossing a single weak zone, shear stresses are mobilized at its interface with the adjacent competent rock, because the latter experiences smaller deformations. The shear stresses reduce the convergences within the weaker zone, particularly when its length is small. As shown, e.g., by Matter et al. (2007) and in more detail by Graziani et al. (2007a), this so-called "wall effect" is also favourable with respect to the risk of TBM jamming.

Due to these considerations, an examination was performed as to whether the variability of the ground behaviour observed in Uluabat could be explained by the existence of weak zones of variable extent and an analysis was conducted into the effect of the length of a weak zone on the required thrust force. Figure 13 and Table 1 (Set 4) show the layout of the problem and the assumed
Fig. 13 Layout of the short fault zone problem investigated with step-by-step calculations

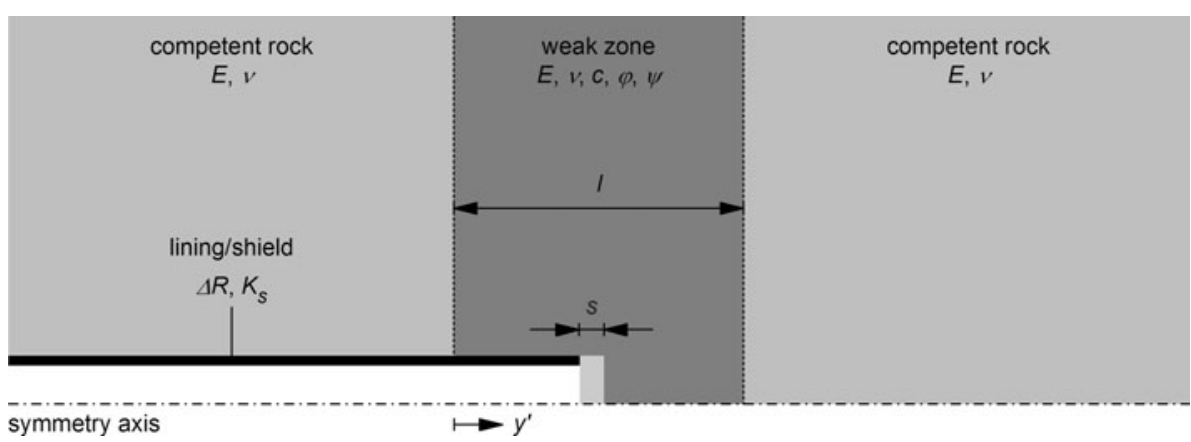


parameters, respectively. The main assumptions are the same as in the last section. In order to reduce the computational cost, the numerical investigations assumed that the behaviour of the competent rock before and after the weaker zone is linearly elastic. Due to the non-uniformity of the conditions in the longitudinal direction, it was not possible to apply the steady state numerical solution method and, therefore, the tunnel excavation and support installation were modelled step-by-step based on a step length $s$ of 0.5 or $1.0 \mathrm{~m}$.

Figure 14 shows the required thrust force $F_{\mathrm{r}}$ as a function of the tunnel face position $y^{\prime}$ (the latter refers to the onset of the critical zone, cf. Fig. 13). The curves apply to weak zones of different lengths $l$. As expected, the required thrust force increases when the TBM enters into the weak zone and decreases when the TBM leaves it. Assuming that practically the entire installed thrust force of $F_{\mathrm{i}}=30 \mathrm{MN}$ is available for overcoming skin friction, the TBM would be able to cope with a 5-10 m thick weak zone. In the case of a weak zone longer than about $10 \mathrm{~m}$, however, the TBM might become trapped. The observed variability might therefore be associated with a sequence of weaker and stronger rock zones.
Figure 15 shows the maximum required thrust force $F_{\mathrm{r}}$ as a function of the length $l$ of the weak zone for step lengths $s$ of 0.5 or $1 \mathrm{~m}$. The shorter the weak zone, the more pronounced will be the wall-effect and the lower will be the risk of shield jamming. In the example of Fig. 15, the wall-effect is remarkable for critical zones shorter than about 10-15 m, i.e., two or three tunnel diameters. For long fault zones and a step length of $s=0.5 \mathrm{~m}$, the results of the step-by-step solution agree well with those obtained by the steady state method. On the contrary, for the reasons mentioned in Sect. 2.3, adopting a longer round length (e.g., $s=1 \mathrm{~m}$ ) leads to an underestimation of the required thrust force $F_{\mathrm{r}}$ (by $15 \%$ in this example).

\section{An Example of a Gripper TBM}

\subsection{Introduction}

Other than in the case of shielded TBMs, where the support characteristics are largely pre-defined (precast segments, maybe of variable reinforcement content), a certain degree of flexibility exists in gripper TBMs with respect to the
Fig. 14 Required thrust force $F_{\mathrm{r}}$ as a function of the position $y^{\prime}$ of the tunnel face (cf. Fig. 13) for different lengths $l$ of the weak zone (step length $s=1 \mathrm{~m}$, radial gap size $\Delta R=3 \mathrm{~cm}$, shield length $L=12 \mathrm{~m}$, skin friction coefficient $\mu=0.50$, safety factor for the required thrust force $S F=1.0$; other parameters according to Table 1, Set 4)

Fig. 15 Maximum required thrust force $F_{\mathrm{r}}$ in the weak zone as a function of their length $l$ (radial gap size $\Delta R=3 \mathrm{~cm}$, shield length $L=12 \mathrm{~m}$, skin friction coefficient $\mu=0.50$, safety factor for the required thrust force $S F=1.0$; other parameters according to Table 1, Set 4)
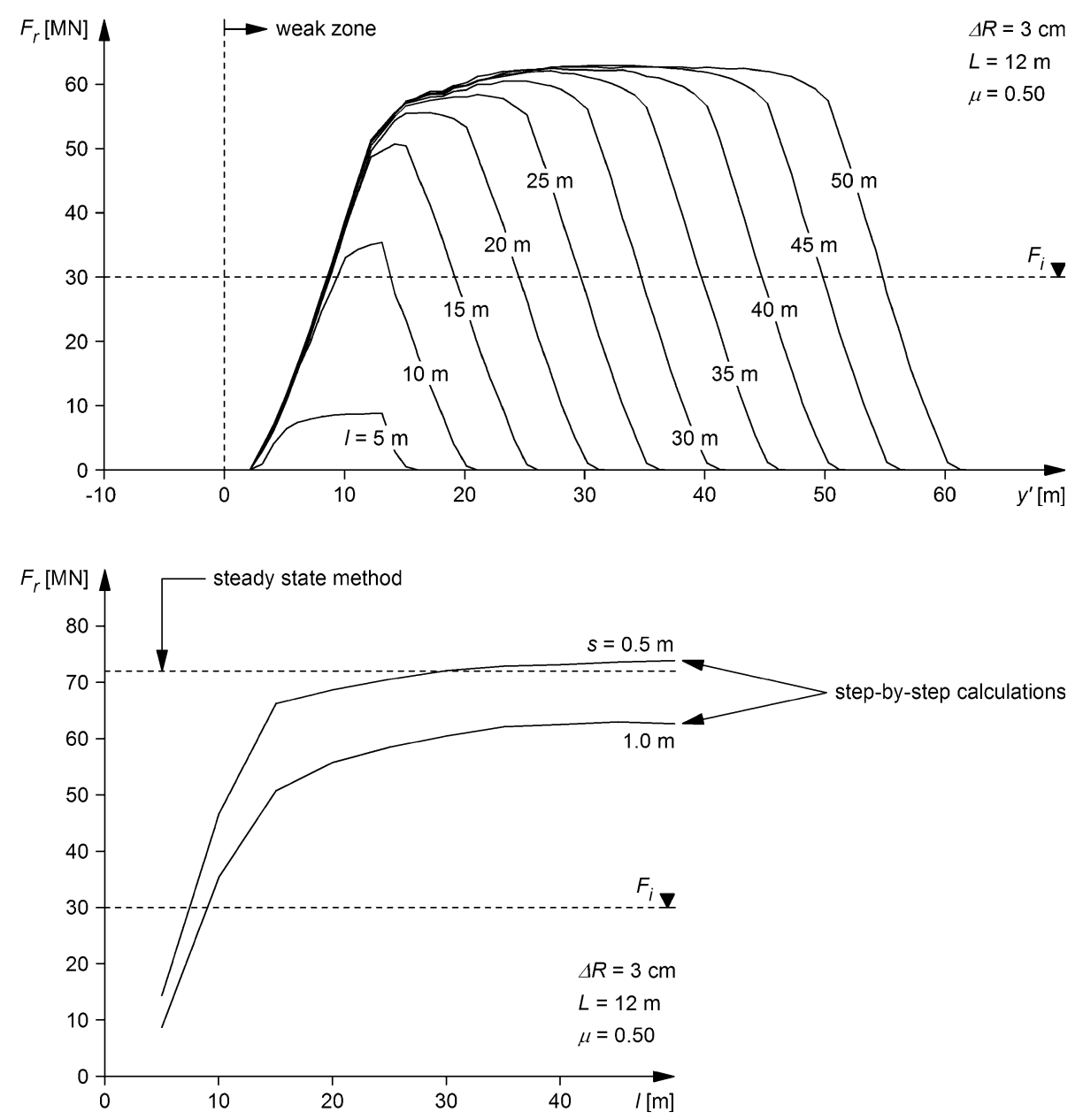
means and quantities of support. Due to the largely predefined boring diameter, decision-making is nevertheless constricted to a relatively narrow space as the geometrical constraints of the tunnelling equipment limit both the admissible convergence and the possible thickness of the tunnel support. Decision-making may also be particularly challenging because of the conflictive criteria often existing in squeezing ground: stabilizing interventions behind the machine are generally possible only in some locations that are dictated by the TBM design. In order to avoid problems such as a violation of the clearance profile, a high quantity of support may have to be installed shortly after excavation, i.e., behind the cutter head. This, however, slows down TBM advance and, in the case of timedependent rock behaviour, increases the risk of the machine becoming trapped.

The present section discusses the effect of different support types based upon the results of numerical investigations carried out by the authors (Anagnostou and Ramoni 2007) for the $14.2 \mathrm{~km}$ long Faido Section of the Gotthard Base Tunnel in Switzerland. The tunnel is currently under construction by means of two gripper TBMs $(D=9.43 \mathrm{~m})$ having $5 \mathrm{~m}$ long cutter head shields and installed thrust forces of 27.5 MN. The TBM drives in the Faido Section started in July and October 2007, respectively, with manually shifted gauge cutters $(D=9.50 \mathrm{~m})$. Squeezing related phenomena were observed in the so-called "Lucomagno-Gneiss" - a metamorphic, micaceous, crystalline rock-at a depth of $1600 \mathrm{~m}$ (estimated initial stress $\sigma_{0}=40 \mathrm{MPa}$ ). In a $250 \mathrm{~m}$ long stretch, convergences in the roof (of up to $5-10 \mathrm{~cm}$ in the eastern tube and of up to $25 \mathrm{~cm}$ in the western tube) and in the tunnel floor (of up to $30 \mathrm{~cm}$ in the eastern tube and of up to $75 \mathrm{~cm}$ in the western tube) caused damage to the tunnel support and jamming of the back-up trailers (Böckli 2008; Boissonnas 2008; Flury and Priller 2008; Gollegger et al. 2009; Herrenknecht et al. 2009). Deformations of up to $10 \mathrm{~cm}$ occurred within the short interval between the working face and the shield tail, thus using up most of the convergence margin offered by the shield articulation, without however to immobilize the TBM.

\subsection{Investigations}

The aim of the investigations was to find out which support type would present the lowest risks (with respect to a series of squeezing-related hazard scenarios), thereby maximizing the range of manageable squeezing conditions. For this purpose, the authors analysed the hazard scenarios, (1), jamming of the shield, (2), overstressing of the tunnel support and, (3), violation of the clearance profile for a series of hypothetical rock mass constants covering a wide range of squeezing intensity. The parameterization of the squeezing intensity was done based on the radial displacement that would occur in the theoretical case of an unsupported opening. Figure 16a shows the range of ground response curves for the rock types under consideration: the radial displacement $u$ amounts to 2-9\% of the tunnel radius $R$, while, for a given convergence, the ground response curve may be more or less curved depending on the uniaxial compressive strength $f_{\mathrm{c}}$ and on the Young's modulus $E$ of the ground. The values of the friction angle, the dilatancy angle and the Poisson's ratio were fixed to $\varphi=35^{\circ}, \psi=5^{\circ}$ and $v=0.30$, respectively. Figure $16 \mathrm{~b}$ shows the value pairs $\left(f_{\mathrm{c}}, E\right)$ considered in the numerical analyses. They account for different magnitudes of the
Fig. 16 Range of the ground response curves (a) and uniaxial compressive strengths $f_{\mathrm{c}}$ and Young's moduli $E$ (b) of the rock types considered in the numerical computations (initial stress $\sigma_{0}=40 \mathrm{MPa}$; other parameters according to Table 2)

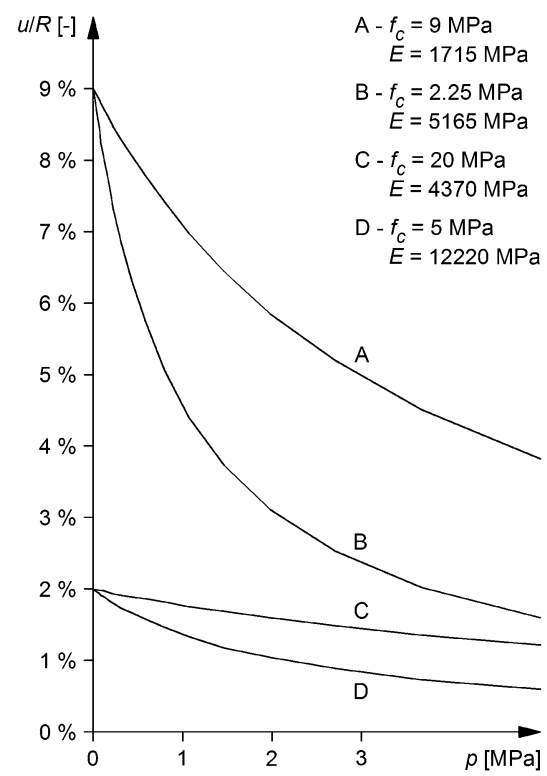

(a)

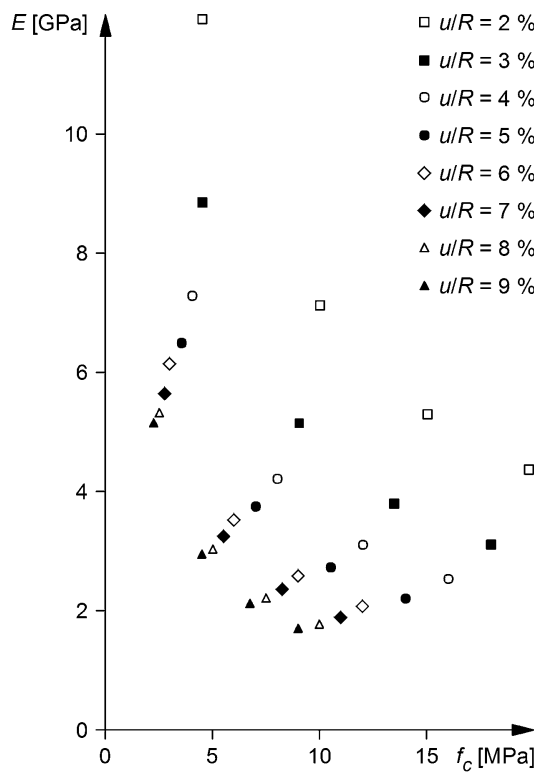

(b) 
convergence of an unsupported opening and for different curvatures of the ground response curve. In the present paper, only the results for the material constants from Table 2 will be presented, as the curvature of the ground response curve does not significantly affect the main conclusions in the present case. The term "rock mass type" used hereafter refers to the parameters of Table 2 .

The numerical calculations were based upon an axisymmetric model with uniform support characteristics over the tunnel cross-section. The assumption of rotational symmetry represents a strong simplification in the present case in view of the observed asymmetric ground deformations. Table 3 shows the investigated tunnel support types. The systems $R S 15$ and $R S 25$ are practically rigid supports including a 15 or $25 \mathrm{~cm}$ thick shotcrete ring, respectively. The systems YS15/S5, YS15/C5, YS15/C15 and $Y S 25 / C 15$ are yielding supports with a 15 or $25 \mathrm{~cm}$ thick shotcrete ring incorporating either $5 \mathrm{~cm}$ thick Styrofoam plates (which can be compressed completely) or $15 \mathrm{~cm}$ thick high ductility concrete elements which can

Table 2 Assumed parameter values for the "rock mass types"

\begin{tabular}{lllllllll}
\hline Parameter & \multicolumn{1}{l}{ Rock mass type } \\
\cline { 2 - 8 } & 1 & 2 & 3 & 4 & 5 & 6 & 7 & 8 \\
\hline$u / R(\%)$ & 2 & 3 & 4 & 5 & 6 & 7 & 8 & 9 \\
$f_{\mathrm{c}}(\mathrm{MPa})$ & 10.0 & 9.0 & 8.0 & 7.0 & 6.0 & 5.5 & 5.0 & 4.5 \\
$E(\mathrm{MPa})$ & 7,140 & 5,140 & 4,225 & 3,750 & 3,525 & 3,235 & 3,055 & 2,950 \\
$v(-)$ & 0.30 & & & & & & & \\
$\varphi\left({ }^{\circ}\right)$ & 35 & & & & & & & \\
$\psi\left({ }^{\circ}\right)$ & 5 & & & & & & & \\
\hline
\end{tabular}

experience a yield strain of about 50\% (Solexperts 2007). All of the support types include steel sets (TH 36) at $1 \mathrm{~m}$ spacings and with sliding connections in the case of the yielding support systems. In addition to the support types of Table 3, the hypothetical case of an unsupported tunnel was also considered for comparison purposes and as a simplified model of very light tunnel support.

For all support cases the assumption was made that the tunnel support is installed immediately behind the shield, i.e., at a distance of $5 \mathrm{~m}$ from the working face. Concerning overcut, two radial gap sizes of $\Delta R=6$ or $12 \mathrm{~cm}$ have been considered, taking into account the shifting of the gauge cutters and the kinematics of the articulated shield.

The computational model simulates the support types described above by mixed, non-linear boundary conditions according to the different characteristic lines (Fig. 17). The latter take due account of the characteristic lines of the different support components as well to the sizes and the number of the yielding elements, including the sliding connections of the steel sets. The Appendix shows the detailed computation of the characteristic line for the example of support type $Y S 25 / C 15$. The time-dependency of the shotcrete stiffness was taken into account in a simplified way by adopting a reduced Young's modulus of $E_{\mathrm{sc}}=10 \mathrm{GPa}$. For a more rigorous computation of the characteristic line of a yielding support, the reader is referred to Radoncic et al. (2009).

\subsection{Discussion of the Results}

The numerical analyses have been carried out for all combinations of rock and support types (Fig. 16b; Table 3,

Table 3 Investigated support systems

\begin{tabular}{|c|c|c|c|c|c|}
\hline & \multirow[t]{2}{*}{ Shotcrete thickness $d_{1}(\mathrm{~cm})$} & \multirow[t]{2}{*}{ Steel set type } & \multicolumn{3}{|l|}{ Deformable elements } \\
\hline & & & Number $\times$ yield deformation $(\mathrm{cm})$ & Material & Height $d_{2}(\mathrm{~cm})$ \\
\hline \multicolumn{6}{|c|}{ Rigid support } \\
\hline$R S 15$ & 15 & TH 36 & & & \\
\hline$R S 25$ & 25 & TH 36 & & & \\
\hline \multicolumn{6}{|c|}{ Yielding support } \\
\hline$Y S 15 / S 5$ & 15 & TH 36 & $4 \times 5.0$ & Styrofoam & 5 \\
\hline$Y S 15 / C 5$ & 15 & TH 36 & $4 \times 2.5$ & Concrete & 5 \\
\hline$Y S 15 / C 15$ & 15 & TH 36 & $4 \times 7.5$ & Concrete & 15 \\
\hline$Y S 25 / C 15$ & 25 & TH 36 & $4 \times 7.5$ & Concrete & 15 \\
\hline
\end{tabular}

Rigid support

Yielding support
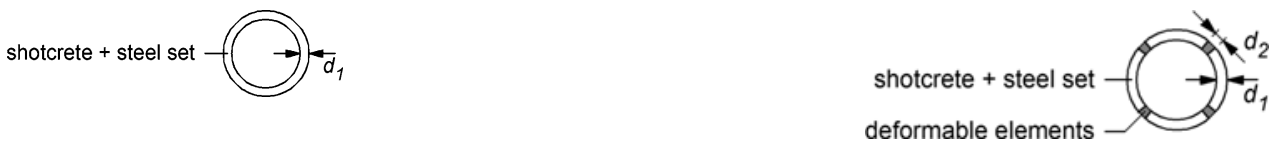
Fig. 17 Characteristics lines (ground pressure $p$ as a function of the radial displacement of the lining $u_{1}$ ) of the investigated support systems (cf. Table 3)

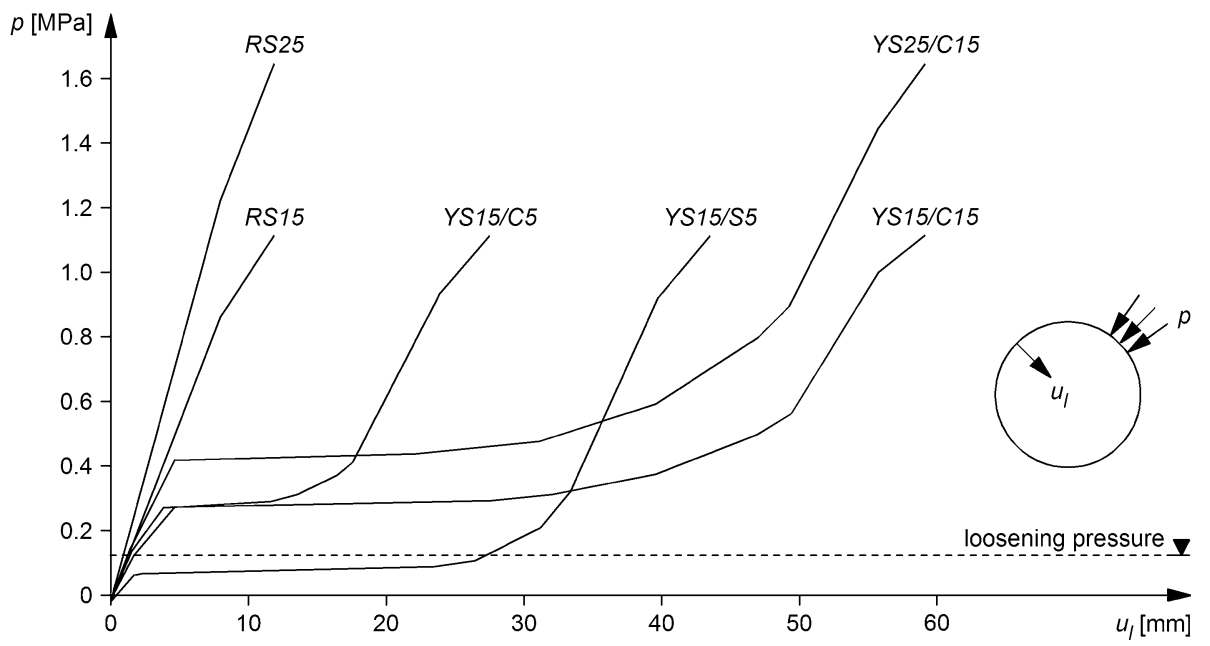

respectively). The main results of each numerical analysis are the rock pressure distribution along the shield and the tunnel and the deformations of the bored profile. These results were evaluated with respect to the following criteria:

1. Is the installed thrust force sufficient to overcome frictional resistance?

2. Is the structural safety of the tunnel support sufficient?

3. Do the rock mass convergences violate the clearance profile ("underprofile")?

Concerning the thrust force requirements, the investigations considered the conditions both during ongoing excavation and for restart after a standstill. These are different with respect to the skin friction coefficient $-\mu=0.30$ or 0.45, respectively, cf. Gehring (1996) —and to the thrust force needed for boring $\left(F_{\mathrm{b}}=17 \mathrm{MN}\right)$. Furthermore, the evaluation disregarded possible limitations of the available thrust force due to problems with the gripper bracing-a reasonable assumption considering the crystalline character of the rock. The operational stage "ongoing excavation" is the relevant one in the present case. This is because the thrust force needed for boring (which in the present example amounts to $62 \%$ of the installed thrust force) overweighs the positive effect of having a lower skin friction coefficient.

Table 4 Combined evaluation of the hazard scenarios "shield jamming", "support overstressing" and "underprofile" for ongoing excavation (support systems according to Table 3, ground parameters according to Table 2)

\begin{tabular}{|c|c|c|c|c|c|c|c|c|c|}
\hline \multirow[b]{2}{*}{ Overboring } & \multirow[b]{2}{*}{ Support system } & \multicolumn{8}{|c|}{ Rock mass type } \\
\hline & & 1 & 2 & 3 & 4 & 5 & 6 & 7 & 8 \\
\hline \multirow{7}{*}{$6 \mathrm{~cm}$} & Unsupported & 0 & B & B & B & B & B & A & A \\
\hline & $R S 15$ & 0 & C & A & A & A & A & A & A \\
\hline & $R S 25$ & 0 & C & A & A & A & A & A & A \\
\hline & YS15/S5 & 0 & B & B & A & A & A & A & A \\
\hline & YS15/C5 & 0 & B & A & A & A & A & A & A \\
\hline & YS15/C15 & 0 & B & B & B & A & A & A & A \\
\hline & YS25/C15 & 0 & B & B & B & B & A & A & A \\
\hline \multirow{7}{*}{$12 \mathrm{~cm}$} & Unsupported & 0 & 0 & 0 & 0 & B & B & A & A \\
\hline & $R S 15$ & 0 & C & C & C & C & C & C & A \\
\hline & $R S 25$ & 0 & C & C & C & C & C & C & A \\
\hline & YS15/S5 & 0 & 0 & 0 & 0 & C & A & A & A \\
\hline & YS15/C5 & 0 & 0 & 0 & C & C & C & A & A \\
\hline & YS15/C15 & 0 & 0 & 0 & 0 & 0 & A & A & A \\
\hline & YS25/C15 & 0 & 0 & 0 & C & C & A & A & A \\
\hline
\end{tabular}

$O$ Installed thrust force sufficient, structural safety of the tunnel support warranted, no under-profile; $A$ installed thrust force not sufficient, structural safety of the tunnel support not warranted and/or under-profile; $B$ installed thrust force not sufficient, structural safety of the tunnel support warranted, no under-profile; $C$ installed thrust force sufficient, structural safety of the tunnel support not warranted and/or under-profile 
In order to evaluate structural safety, the lining hoop stress was compared to the shotcrete strength not only at the final state (assuming $f_{\mathrm{c}, \mathrm{sc}}=25 \mathrm{MPa}$ ) far behind the TBM, but also at a section located at $2 \mathrm{~m}$ behind the shield in order to check overstressing of the green shotcrete. The early strength of the shotcrete at this section was taken to $f_{\mathrm{c}, \mathrm{sc}}=10 \mathrm{MPa}$ according to lab tests on 8-10 h old specimens. This age is relevant for the shotcrete loading taking into account the actual gross advance rate of $v=5-6 \mathrm{~m} / \mathrm{d}$.

In order to check the clearance profile, the space used up by the actual thickness of each support system was taken into account. (A thicker shotcrete lining needs more space but leads to smaller deformations because of its higher stiffness.)

Table 4 shows the combined evaluation of the criteria mentioned above. The yielding support systems in combination with the bigger overcut $(\Delta R=12 \mathrm{~cm})$ cover the widest spectrum of geological conditions (this conclusion is also true for the other parameter combinations of Fig. 16b).

The rigid support systems (RS15 and RS25) have a positive effect with respect to the thrust force requirements because they rapidly offer a high resistance to the ground deformations close to the shield (cf. Sect. 4.4; Fig. 11). This becomes evident by comparing the distribution of the ground pressure $p$ acting upon the shield and the lining for the support systems RS15 (rigid) and YS15/S5 (yielding). As shown in Fig. 18, the shield remains practically unloaded in the first case, while a high load develops at the shield tail in the second case and may immobilize or even damage the shield. Nevertheless, in the most of the cases that were investigated, the load developing upon the rigid support systems is much higher than their bearing capacity. Even a simplified estimation of their bearing capacitydisregarding possible bending moments (axial symmetry)_-shows an insufficient level of structural safety. Applying a thicker shotcrete layer $\left(d_{1}=25\right.$ instead of $15 \mathrm{~cm}$ ) does not improve matters substantially. At this point, it has also to be noted that the load developing upon the rigid support systems close to the shield depends strongly on the assumed stiffness of the shotcrete. If the assumed "average" value of $E_{\mathrm{sc}}=10 \mathrm{GPa}$ overestimates the actual Young's modulus of the green shotcrete, the computations overestimate the ground pressure acting upon the lining near to the shield and, consequently, the positive longitudinal arching effect.

Limitations also exist, however, for yielding supports. Taking into account the boring diameter, the clearance profile and the space needed for the final lining, $40 \mathrm{~cm}$ in the tunnel radius were available for the thickness of the tunnel support and for admitting some load-reducing convergences without violating the clearance profile.

A very light support (a practically unsupported tunnel) is theoretically satisfactory. Assuming that the tunnel support would use $10 \mathrm{~cm}$ of the tunnel radius, the calculated deformations would violate the clearance profile only for rock mass types 7 and 8 . However, such a solution would not allow rock deformations to be controlled and would be unacceptable with regard to possible gravity-driven instabilities.

After Table 4, the support systems YS15/S5 and $Y S 15 / C 15$ employing $15 \mathrm{~cm}$ shotcrete in combination with Styrofoam or high ductility concrete elements are the most advantageous. (The first one has been successfully applied, while the second one has only been tested along $30 \mathrm{~m}$ of the TBM drive shortly before the end of the critical stretch.) However, when comparing these systems, it has to be borne in mind that the admission of ground deformations may cause more loosening of the rock. The thickness of the plastic zone $(3.7 \mathrm{~m})$, which results from the calculations, provides a rough indication of the extent of the loosened zone and thus of the possible loosening pressure. Assuming a unit weight of the rock of $25 \mathrm{kN} / \mathrm{m}^{2}$, the resulting loosening pressure amounts to about $90-100 \mathrm{kPa}$. This value is lower than the yield pressure of the support system with the high ductility concrete elements (YS15/C15),
Fig. 18 Ground pressure $p$ acting upon the shield and the lining ("rock mass type" 6 according to Table 2, shield length $L=5 \mathrm{~m}$, radial gap size $\Delta R=12 \mathrm{~cm}$, support system $R S 15$ or $Y S 15 / S 5$ according to Table 3; other parameters according to Table 1 , Set 5)

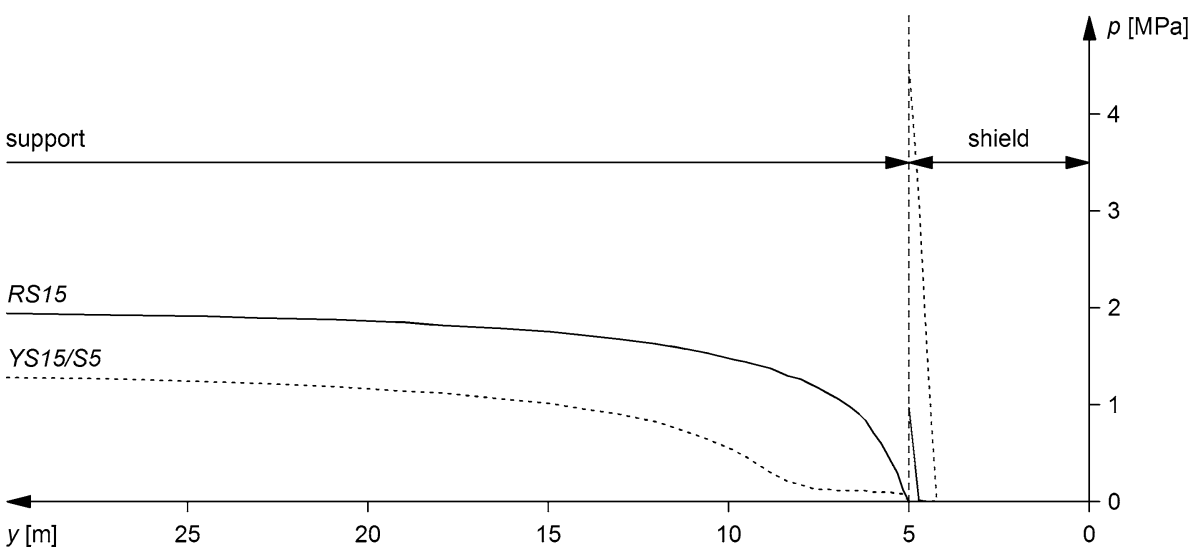


but exceeds the resistance of the support system with the Styrofoam elements (YS15/S5). Consequently, the latter might start to deform under the action of the loosened rock mass (Fig. 17) and would use up its deformation capacity with the consequence that it would behave like the rigid support $R S 15$ during the squeezing phase.

The support system YS15/S5 would therefore be equivalent to $Y S 15 / C 15$ only if combined with 5-6 m long rock bolts at the crown that would bear the loosening pressure of about $100 \mathrm{kPa}$. On the other hand, and as shown by tunnelling experience, the application of the support system $Y S 15 / C 15$ presupposes-due to the relatively high stiffness of the high ductility concrete elements-that the shotcrete develops a sufficiently high early strength (i.e., at least the same compressive strength as the deformable concrete elements). This may be a problem if the time-development of the shotcrete strength is too slow in relation to the TBM advance. This aspect may be relevant also in conventional tunnelling but it is expected to be less common because of the lower advance rates.

\section{Conclusions}

The numerical solution method presented and applied in this paper represents a powerful tool for the simulation of a TBM drive in homogeneous squeezing ground. The mixed boundary condition developed for the ground-support interface allows an accurate simulation of the shield and of any kind of tunnel support. The application of the steady state method makes it possible to solve the advancing tunnel heading problem in one single computation step with a major reduction of the computation time, thus allowing comprehensive parametric studies to be performed at a justifiable cost. The effects of changes in ground conditions as well as the suitability of modifications to the TBM layout and the tunnel support can therefore be investigated easily and quickly.

The steady state method can be applied not only to the standard linearly elastic, perfectly plastic material model (Mohr-Coulomb) assumed in the present paper, but also to a large category of problems including creep or consolidation of the ground as well as time dependencies of the support behaviour (Anagnostou 2007). However, for the investigation of heterogeneous ground conditions, the commonly used step-by-step method remains to be applied. A comparative analysis involving a short critical zone (striking orthogonally to the tunnel axis) has shown that a reduction of the step length improves accuracy with respect to the required thrust force-although this comes, of course, at a higher computational cost. The later is particularly high for non-hydrostatic initial stress conditions as well as for faults striking with a small angle to the tunnel axis because such cases call for true three-dimensional numerical analyses.

Acknowledgments This paper evolved within the framework of the research project "Design aids for the planning of TBM drives in squeezing ground", which is being carried out at the ETH Zurich, supported by the Swiss Tunnelling Society (STS) and financed by the Swiss Federal Roads Office (FEDRO).

\section{Appendix: Computation of the Characteristic Line of the Yielding Support YS25/C15}

In order to carry out the numerical investigations of Sect. 6, the characteristic line (i.e., the relationship between the ground pressure $p$ and the radial displacement $u_{1}$ ) of each considered tunnel support (cf. Table 3; Fig. 17) has been implemented in the computational model. As an example, this Appendix will illustrate the detailed computation of the characteristic line of the tunnel support $Y S 25 / C 15$. This support system is composed of three basic elements (Fig. 19): (1) a $25 \mathrm{~cm}$ thick shotcrete ring; (2) $15 \mathrm{~cm}$ high ductility concrete elements; (3) steel sets (TH36) at $1 \mathrm{~m}$ spacings having sliding connections.

For the computation of the characteristic line, it has to be considered that the elements (1) and (2) are connected in series, while the element (3) is connected in parallel with the subsystem (1-2). The elements of a serial connection have the same hoop force (due to equilibrium condition) but experience different deformations. On the other hand, elements connected in parallel experience the same deformations (compatibility condition), while the hoop force is different. Therefore, the correct computation of the characteristic line of the support system requires first the formulation of the relationship between hoop force $N$ and radial displacement $u_{1}$ for each subsystem. Because of this, this Appendix will first compute this relationship for the subsystems (1-2) and (3). Later, the same will be done for the entire system (1-2//3), leading thus to the characteristic line of the support system under investigation.

\section{Shotcrete Ring with High Ductility Concrete Elements}

Taking into account the well-known kinematic relations, the radial displacement $u_{1,1-2}$ of the subsystem (1-2) reads as follows:

$u_{1,1-2}=\varepsilon_{\mathrm{t}, 1-2} R$,

where $\varepsilon_{\mathrm{t}, 1-2}$ is the hoop strain and $R$ the tunnel radius. The hoop strain $\varepsilon_{\mathrm{t}, 1-2}$ corresponds to the ratio between the reduction of the circumference $\Delta C_{1-2}$ of the ring-due to the tangential deformation of both elements (1) and (2)and its initial circumference $C$ : 
Fig. 19 Sketch of the support system $Y S 25 / C 15$
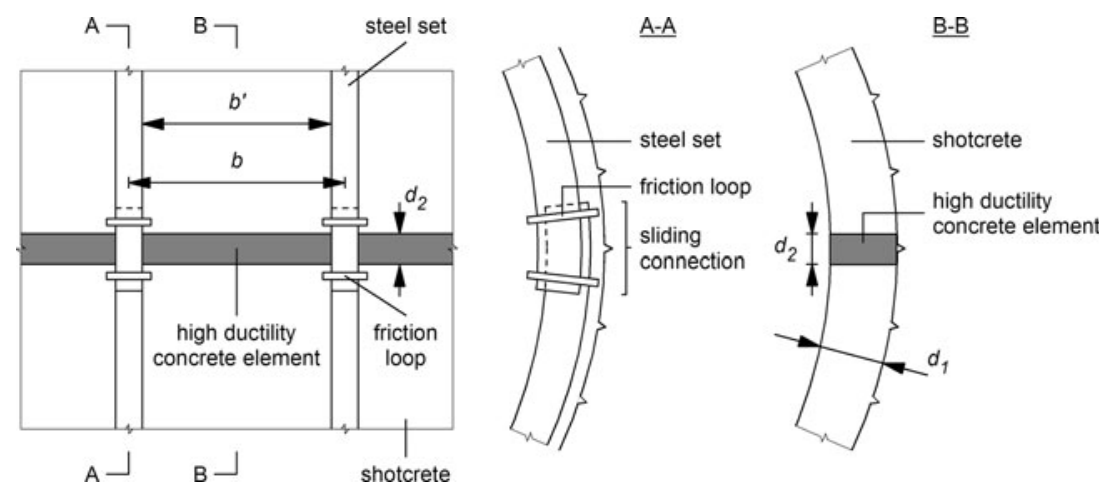

$\varepsilon_{\mathrm{t}, 1-2}=\frac{\Delta C_{1-2}}{C}=\frac{\Delta C_{\mathrm{sc}}+\Delta C_{\mathrm{ce}}}{2 R \pi}$.

The reduction of the arc length $\Delta C_{\mathrm{sc}}$ of the shotcrete ring is:

$\Delta C_{\mathrm{sc}}=\varepsilon_{\mathrm{t}, \mathrm{sc}} C_{\mathrm{sc}}=\frac{\sigma_{\mathrm{t}, \mathrm{sc}}}{E_{\mathrm{sc}}}\left(2 R \pi-n_{\mathrm{ce}} d_{2}\right)$,

where $E_{\mathrm{sc}}$ is the Young's modulus of the shotcrete, while $n_{\text {ce }}$ and $d_{2}$ are the number and the height of the deformable concrete elements incorporated in the shotcrete ring, respectively (Fig. 19). The hoop stress $\sigma_{\mathrm{t}, \mathrm{sc}}$ depends on the hoop force $N_{\mathrm{sc}}$ :

$\sigma_{\mathrm{t}, \mathrm{sc}}=\frac{N_{\mathrm{sc}}}{b^{\prime} d_{1}} \leq f_{\mathrm{c}, \mathrm{sc}}$

where $b^{\prime}$ is the width of the shotcrete ring between two steel sets (i.e., the steel set clear distance), $d_{1}$ is the thickness of the shotcrete layer and $f_{\mathrm{c}, \mathrm{sc}}$ is the uniaxial compressive strength of the shotcrete. The reduction of the arc length $\Delta C_{\mathrm{ce}}$ due to the deformation of the high ductility concrete elements reads as follow:

$\Delta C_{\mathrm{ce}}=\varepsilon_{\mathrm{t}, \mathrm{ce}} C_{\mathrm{ce}}=\varepsilon_{\mathrm{t}, \mathrm{ce}} n_{\mathrm{ce}} d_{2}$.

The hoop strain $\varepsilon_{\mathrm{t}, \mathrm{ce}}$ depends on the hoop stress $\sigma_{\mathrm{t}, \mathrm{ce}}$ :

$\varepsilon_{\mathrm{t}, \mathrm{ce}}=f\left(\sigma_{\mathrm{t}, \mathrm{ce}}\right)$.

Equation 9 is the working line of the applied deformable concrete elements and is provided by the manufacturer.
Figure 20 shows graphically the relationship used in this paper. Analogous to Eq. 7, the hoop stress $\sigma_{\mathrm{t}, \mathrm{ce}}$ can be formulated as a function of the hoop force $N_{\mathrm{ce}}$ :

$\sigma_{\mathrm{t}, \mathrm{ce}}=\frac{N_{\mathrm{ce}}}{b^{\prime} d_{1}} \leq f_{\mathrm{c}, \mathrm{ce}}$

where $f_{\mathrm{c}, \mathrm{ce}}$ is a maximum compressive stress considered for the calculations (cf. Fig. 20). Taking into account the Eqs. 5-10 as well as that the elements (1) and (2) are connected in series, i.e., that

$N_{1-2}=N_{\mathrm{sc}}=N_{\mathrm{ce}}$,

the relationship between hoop force $N_{1-2}$ and radial displacement $u_{1,1-2}$ for the subsystem (1-2) of Eq. 4 can be now computed (Fig. 21a).

\section{Steel Sets Having Sliding Connections}

Figure 21b shows the assumed relationship between hoop force $N_{3}$ and radial displacement $u_{1,3}$ for the subsystem (3). Neglecting stability problems (buckling), the idealized behaviour up to failure of a steel set having sliding connections can be divided in four phases (Fig. 21b). In phase A, the steel set deforms elastically. When the hoop force $N_{3}$ reaches the yield load $N_{\mathrm{y}}$, the sliding connections start to close (phase B) until the deformation capacity $\Delta u_{1,3, \mathrm{~B}}$ is exhausted. In phase $\mathrm{C}$, the sliding connections are closed and the steel set deforms further elastically. When the hoop force $N_{3}$
Fig. 20 Assumed loaddeformation behaviour of the high ductility concrete elements after Solexperts (2007)

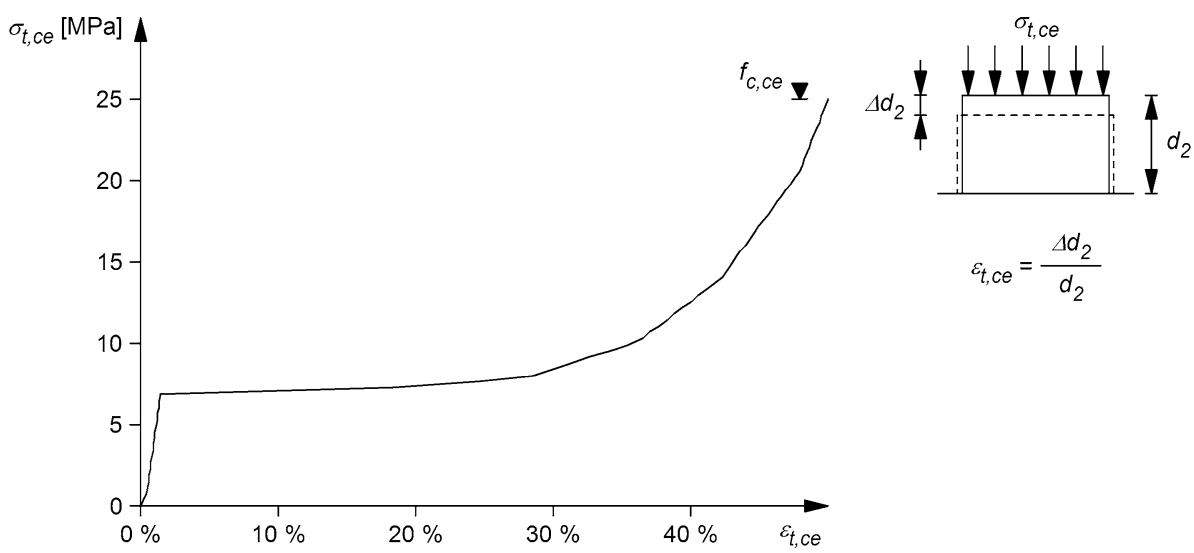


Fig. 21 Hoop force $N$ as a function of the radial displacement $u_{1}$ : a shotcrete ring with high ductility concrete elements, b steel sets having sliding connections, $\mathbf{c}$ support system YS $25 / C 15$

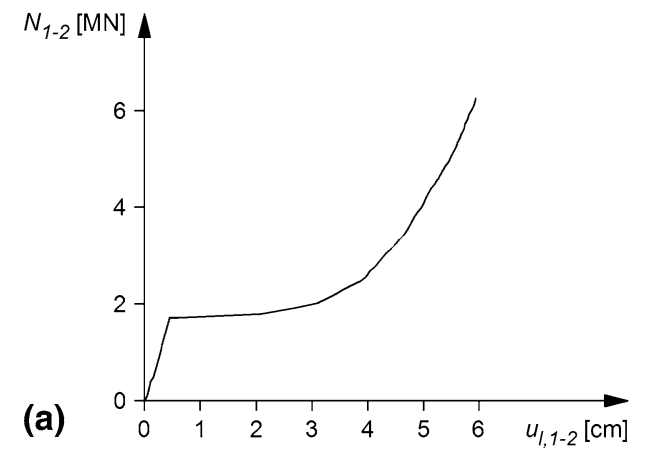

shotcrete ring with high ductility concrete elements

$R=4.75 \mathrm{~m}$

$d_{1}=25 \mathrm{~cm}$

$E_{s C}=10 \mathrm{GPa}$

$f_{C, s C}=25 \mathrm{MPa}$

$n_{c e}=15 \mathrm{~cm}$

$d_{2}=15 \mathrm{~cm}$

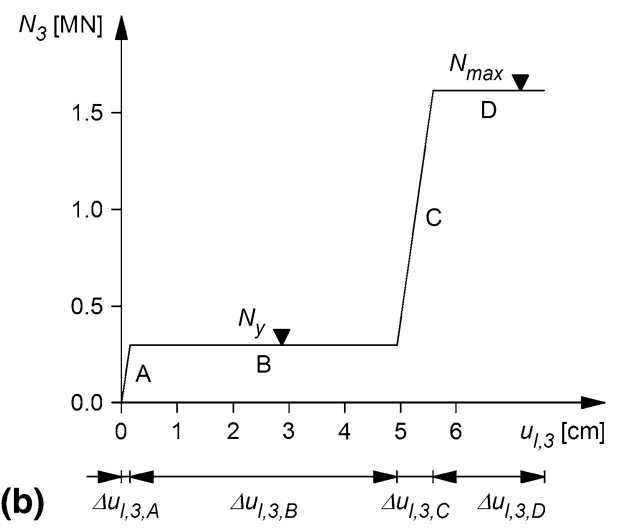

$N[\mathrm{MN}]$

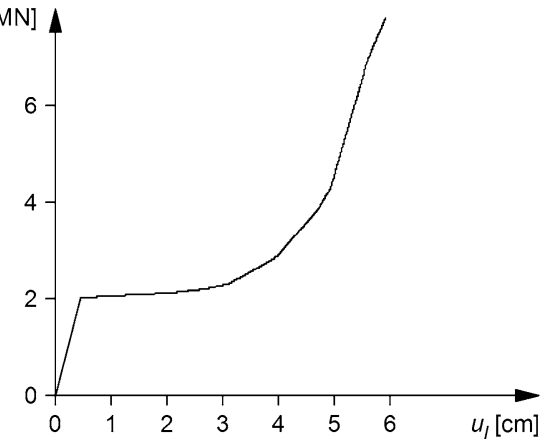

steel sets having sliding connections

$b=b^{\prime}=1 \mathrm{~m}$

$A_{\text {ss }}=46 \mathrm{~cm}^{2}$

$E_{S S}=210 \mathrm{GPa}$

$f_{y, s s}=350 \mathrm{MPa}$

$\varepsilon_{\text {SS, } \max }=15 \%$

$n_{f}=2$

$N_{f}=150 \mathrm{kN}$

support system YS25/C15 reaches the yield load of the steel set $N_{\max }$, the steel set deforms further plastically since it reached its failure strain.

Analogous to Eq. 4, the radial deformation $u_{1,3}$ of the subsystem (3) reads as follows:

$u_{1,3}=\varepsilon_{\mathrm{t}, 3} R$.

Therefore, the increase of the radial deformation $\Delta u_{1,3, \mathrm{i}}$, which occurs in each phase (cf. Fig. 21), is

$\Delta u_{1,3, \mathrm{i}}=\Delta \varepsilon_{\mathrm{t}, 3, \mathrm{i}} R$,

where $i=\mathrm{A}, \mathrm{B}, \mathrm{C}$ or D. Analogous to Eq. 5, the increase of the hoop strain $\Delta \varepsilon_{t, 3, i}$ corresponds to the ratio between the reduction of the circumference $\Delta C_{3, \mathrm{i}}$ of the subsystem (3) - due to the tangential deformation of the steel set or of the sliding connections-and its initial circumference $C$ before deformation:
$\Delta \varepsilon_{\mathrm{t}, 3, \mathrm{i}}=\frac{\Delta C_{3, \mathrm{i}}}{C}$

In phase $\mathrm{A}$, as mentioned above, only the steel set deforms. Therefore, $\Delta C_{3, \mathrm{~A}}$ only depends on the increase of the hoop stress $\Delta \sigma_{\mathrm{t}, \mathrm{ss}, \mathrm{A}}$ in the steel set (occurred in phase A) and on the Young's modulus of the steel set $E_{\mathrm{ss}}$ :

$\Delta C_{3, \mathrm{~A}}=\varepsilon_{\mathrm{t}, \mathrm{ss}, \mathrm{A}} C_{\mathrm{ss}}=\frac{\Delta \sigma_{\mathrm{t}, \mathrm{s}, \mathrm{A}}}{E_{\mathrm{ss}}} 2 R \pi$,

where $\Delta \sigma_{\mathrm{t}, \mathrm{ss}, \mathrm{A}}$ is

$\Delta \sigma_{\mathrm{t}, \mathrm{ss}, \mathrm{A}}=\frac{N_{\mathrm{y}}}{A_{\mathrm{ss}}}$

and $A_{\mathrm{ss}}$ is the cross-sectional area of the steel set. The yield load $N_{\mathrm{y}}$ depends on the number of friction loops $n_{\mathrm{f}}$ of each sliding connection and on the friction loop resistance $N_{\mathrm{f}}$ : 
$N_{\mathrm{y}}=n_{\mathrm{f}} N_{\mathrm{f}}$.

In phase $\mathrm{B}$, the sliding connections deform and close. The consequent reduction of the circumference $\Delta C_{3, \mathrm{~B}}$ depends on the number of slots and on the maximum slot deformation:

$\Delta C_{3, \mathrm{~B}}=n_{\mathrm{ce}} \frac{d_{2}}{2}$.

In this case, as the steel sets are applied in combination with high ductility concrete elements, the number of slots is equal to the number of deformable concrete elements $n_{\text {ce }}$. The allowed slot deformation has to be chosen according to their deformability. As the deformable concrete elements become practically rigid at a strain of $\varepsilon_{\mathrm{t} \text {,ce }}=50 \%$ (cf. Fig. 20), the maximum slot deformation corresponds to the half of the height $d_{2}$ of the deformable concrete elements.

For the phase $\mathrm{C}$, where only the steel set deforms (the sliding connections closed at the end of phase B), the reduction of the circumference $\Delta C_{3, \mathrm{C}}$ reads as follows:

$\Delta C_{3, \mathrm{C}}=\varepsilon_{\mathrm{t}, \mathrm{ss}, \mathrm{C}} C_{\mathrm{ss}}=\frac{\Delta \sigma_{\mathrm{t}, \mathrm{ss}, \mathrm{C}}}{E_{\mathrm{ss}}} 2 R \pi$,

where

$\Delta \sigma_{\mathrm{t}, \mathrm{ss}, \mathrm{C}}=\frac{N_{\mathrm{max}}-N_{\mathrm{y}}}{A_{\mathrm{ss}}}$.

The yield load of the steel set $N_{\max }$ can be calculated as the product of the yield stress $f_{\mathrm{y}, \mathrm{ss}}$ by the cross-sectional area $A_{\text {ss }}$ of the steel set:

$N_{\max }=f_{\mathrm{y}, \mathrm{ss}} A_{\mathrm{ss}}$.

In phase $\mathrm{D}$, the steel set deforms plastically until the failure strain $\varepsilon_{\mathrm{ss}, \max }$ is reached. Taking account of the elastic deformations, which already occurred in phases $\mathrm{A}$ and $\mathrm{C}$, and assuming that in phase $\mathrm{B}$ the steel set does not experience hoop strain changes, the reduction of the circumference $\Delta C_{3, \mathrm{D}}$ is

$\Delta C_{3, \mathrm{D}}=\Delta C_{\mathrm{ss}, \max }-\left(\Delta C_{3, \mathrm{~A}}+\Delta C_{3, \mathrm{C}}\right)$,

where $\Delta C_{\mathrm{ss}, \max }$ is the maximum reduction of circumference, that the steel set can accommodate up to failure:

$\Delta C_{\mathrm{ss}, \max }=\varepsilon_{\mathrm{ss}, \max } 2 R \pi$.

\section{Support System YS25/C15}

The relationship between hoop force $N$ and radial displacement $u_{1}$ for the entire system $(1-2 / / 3)$ can be now calculated taking into account the parallel connection of the subsystem (1-2) with the subsystem (3), i.e., adding their hoop forces and equating their deformation (Eq. 24 is represented graphically in Fig. 21c):
$\left\{\begin{array}{l}N=N_{1-2}+N_{3} \\ u_{1}=u_{1,1-2}=u_{1,3}\end{array}\right.$.

Finally, the characteristic line of the support system $Y S 25 / C 15$ used for the investigations of Sect. 6 and shown in Fig. 17 can be computed substituting the hoop force $N$ in Eq. 24 with the ground pressure $p$, applying following expression:

$p=\frac{N}{R b}$,

where $b$ is the steel set spacing.

\section{References}

Amberg F (2009) Numerical simulations of tunnelling in soft rock under water pressure. In: ECCOMAS Thematic conference on computational methods in tunnelling, EURO:TUN 2009, Bochum. Aedificatio Publishers, Freiburg, pp 353-360

Anagnostou G (2007) Continuous tunnel excavation in a poroelastoplastic medium. In: Tenth international symposium on numerical models in geomechanics, NUMOG X, Rhodes. Taylor \& Francis Group, London, pp 183-188

Anagnostou G, Cantieni L (2007) Design and analysis of yielding support in squeezing ground. In: The second half century of rock mechanics, 11th Congress of the International Society for Rock Mechanics (ISRM), Lisbon, vol 2. Taylor \& Francis Group, London, pp 829-832

Anagnostou G, Ramoni M (2007) Untersuchungen zum TBMVortrieb südlich der Chiera Synform. AlpTransit Gotthard, Gotthard-Basistunnel, Teilabschnitt Faido, unveröffentlicht, Bericht 071101, 20. Dezember 2007, Professur für Untertagbau, Institut für Geotechnik (IGT), ETH Zürich

Barla G (2001) Tunnelling under squeezing rock conditions. In: Eurosummer-School in Tunnel Mechanics, Innsbruck. Logos Verlag, Berlin, pp 169-268

Billig B, Gipperich C, Wulff M, Schaab A (2007) Ausbausysteme für den maschinellen Tunnelbau in druckhaftem Gebirge. In: Taschenbuch für den Tunnelbau 2008. VGE Verlag GmbH, Essen, pp 223-262

Böckli O (2008) Teilabschnitt Faido-bisherige Erfahrungen mit dem TBM-Vortrieb. In: FGU-Fachtagung für Untertagbau, Swiss Tunnel Congress 2008, Luzern, D0229. SIA, Zürich, pp 49-58

Boissonnas Y (2008) Gotthard Base Tunnel-experience of a TBM excavation with large overburden. In: Building underground for the future, AFTES International Congress Monaco, Montecarlo. Edition specifique, Limonest, pp 247-250

Cantieni L, Anagnostou G (2007) On the variability of squeezing in tunnelling. In: The second half century of rock mechanics, 11th Congress of the International Society for Rock Mechanics (ISRM), Lisbon, vol 2. Taylor \& Francis Group, London, pp 983-986

Cantieni L, Anagnostou G (2009) The effect of the stress path on squeezing behaviour in tunnelling. Rock Mech Rock Eng 42(2):289-318

Cobreros JA, Cervera MM, Herrera M, Conde C (2005) Tunnels de Guadarrama-problèmes géotechniques rencontrés dans un double tunnel de $27 \mathrm{~km}$. Tunnels et ouvrages souterrains $\mathrm{N}^{\circ}$ 190-Supplement juillet/août, pp 5-12 
Einstein HH, Bobet A (1997) Mechanized tunnelling in squeezing rock-from basic thoughts to continuous tunnelling. In: Tunnels for people, ITA World Tunnel Congress '97, Vienna, vol 2. A.A.Balkema, Rotterdam, pp 619-632

Eisenstein ZD, Rossler K (1995) Geotechnical criteria for double shield tunnel boring machines. In: Worldwide innovations in tunnelling, STUVA-Tagung '95, Stuttgart, Forschung + Praxis 36. Alba Fachverlag GmbH + Co. KG, Düsseldorf, pp 192-201

Farrokh E, Rostami J (2008) Correlation of tunnel convergence with TBM operational parameters and chip size in the Ghomroud Tunnel, Iran. Tunn Undergr Space Technol 23(6):700-710

Farrokh E, Rostami J (2009) Effect of adverse geological condition on TBM operation in Ghomroud Tunnel Conveyance Project. Tunn Undergr Space Technol 24(4):436-446

Farrokh E, Mortazavi A, Shamsi G (2006) Evaluation of ground convergence and squeezing potential in the TBM driven Ghomroud Tunnel Project. Tunn Undergr Space Technol 21(5):504-510

Feknous N, Ambrosii G, Henneberg I, Simard R (1996) Design and performance of tunnel support in squeezing rock at Yacambú. In: Rock Mechanics-tools and techniques, 2nd North American Rock Mechanics Symposium, Montréal, vol 1. A.A.Balkema, Rotterdam, pp 803-810

Floria V, Fidelibus C, Repetto L, Russo G (2008) Drainage and related increase of short-term strength of low permeability rock mass. In: Building underground for the future, AFTES International Congress Monaco, Montecarlo. Edition specifique, Limonest, pp 281-284

Flury S, Priller A (2008) Gotthard Base Tunnel-Part-Section Faido. Tunnel 8(4):47-51

Gärber R (2003) Design of deep galleries in low permeable saturated porous media. Thèse No 2721, EPFL Lausanne

Gehring KH (1996) Design criteria for TBM's with respect to real rock pressure. In: Tunnel boring machines-trends in design \& construction of mechanized tunnelling, International lecture series TBM tunnelling trends, Hagenberg. A.A.Balkema, Rotterdam, pp 43-53

Gollegger J, Priller A, Rausch M (2009) The use of open tunnel boring machines in squeezing rock in the Gotthard Base Tunnel. Geomech Tunnel 2(5):591-600

Graziani A, Capata A, Romualdi P (2007a) Analysis of rock-TBMlining interaction in squeezing rock. Felsbau magazin $25 \mathrm{Nr}$ 6:23-31

Graziani A, Ribacchi R, Capata A (2007b) 3D-modelling of TBM excavation in squeezing rock masses. In: Brenner Basistunnel und Zulaufstrecken, Internationales Symposium BBT 2007, Innsbruck. Innsbruck University Press, Innsbruck, pp 143-151

Herrenknecht M (2010) Tunnelling through squeezing rock with TBM. In: Brenner base tunnel and access routes, BrennerCongress 2010, Innsbruck, Ernst \& Sohn Verlag für Architektur und technische Wissenschaften GmbH Berlin, pp 45-54

Herrenknecht M, Böckli O, Bäppler K (2009) Gotthard-Base Tunnel, Section Faido, Previous experience with the use of the TBM. In: Rapid excavation and tunnelling conference, Las Vegas, SME Inc. Littleton, pp 1182-1205

Hisatake M, Iai Y (1993) A method to determine necessary thrust force for TBM. In: Developments in geotechnical engineering, Options for tunnelling 1993, Amsterdam, vol 74. Elsevier Science Publishers B.V. Amsterdam, pp 519-528

ITA (2003) Long traffic tunnels at great depth. ITA Working group $\mathrm{N}^{\circ} 17$ "Long tunnels at great depth". ITA, Lausanne

Jafari A, Mollaee M, Shamsi H (2007) Investigation into ground convergence effect on TBM performance in squeezing ground. In: The second half century of rock mechanics, 11th Congress of the International Society for Rock Mechanics (ISRM), Lisbon. Taylor \& Francis Group, London, vol 2, pp 939-942
John M, Mattle B (2007) Auswirkungen stark druckhafter Gebirgsverhältnisse auf den TBM-Vortrieb. Felsbau magazin 25 Nr. 6:14-21

John M, Schneider E (2007) TBM tunnelling in squeezing rock. Felsbau magazin $25 \mathrm{Nr}$ 6:12

Kawatani T, Tezuka H, Morita R, Shimaya S (1999) Tunnel construction with a large-scale TBM in a collapse-prone poor rock. In: Challenges for the 21st century, ITA World tunnel congress '99, Oslo. A.A. Balkema, Rotterdam, vol 2, pp 895-901

Khademi Hamidi J, Bejari H, Shahriar K, Rezai B (2008) Assessment of ground squeezing and ground pressure imposed on TBM shield. In: 12th International conference of the International Association for Computer Methods and Advances in Geomechanics (IACMAG), Goa. IACMAG, Goa, pp 3907-3914

Kovári K (1986a) Rock deformation problems when using full-facing cutting equipment in rock, Part 1. Tunnel 3(86):236-244

Kovári K (1986b) Rock deformation problems when using full-facing cutting equipment in rock, Part 2. Tunnel 4(86):289-298

Kovári K (1998) Tunnelling in squeezing rock. Tunnel 5(98):12-31

Kovári K, Anagnostou G (1995) The ground response curve in tunnelling through short fault zones. In: 8th congress of the International Society for Rock Mechanics (ISRM), Tokyo. A.A. Balkema, Rotterdam, vol 2, pp 611-614

Kovári K, Ramoni M (2008) Jamming of shield-numerical investigations. In: Uluabat Power Tunnel (Turkey)—TBM drive, unpublished, Report, January 25, 2008

Lavdas N (2010) Einsatzgrenzen vom Tübbingausbau beim TBMVortrieb in druckhaftem Gebirge. Master thesis, ETH Zurich

Lombardi G (1973) Dimensioning of tunnel linings with regard to constructional procedure. Tunnels and Tunnelling 5 No. 4, JulyAugust 1973, pp 340-351

Lombardi G (1981) Bau von Tunneln bei grossen Verformungen des Gebirges. In: Tunnel 81, Internationaler Kongress, Düsseldorf, Band 2. Messegesellschaft mbH NOEWA, Düsseldorf, und Deutsche Gesellschaft für Erd- und Grundbau e.V. Essen, pp 351-384

Lombardi G, Panciera A (1997) Problems with TBM \& linings in squeezing ground. Tunn Tunn Int 29(6):54-56

Lombardi G, Neuenschwander M, Panciera A (2009) Gibraltar Tunnel Project update-the geomechanical challenges. Geomech Tunnel 2(5):578-590

Matter J, Stauber A, Bauer F, Daller J (2007) ÖBB Wienerwaldtunnel-Erfahrungen aus dem Vortrieb. In: FGU-Fachtagung für Untertagbau, Swiss Tunnel Congress 2007, Luzern, D0222, SIA, Zürich, pp 101-112

Moulton BG, Cass DT, Nowak DE, Poulin RM (1995) Tunnel boring machine concept for converging ground. In: Rapid excavation and tunnelling conference, San Francisco. SME Inc. Littleton, pp 509-523

Nguyen Minh D, Corbetta F (1991) Nouvelle méthodes de calcul des tunnels revêtus incluant l'effet du front de taille. In: 7th congress of the International Society for Rock Mechanics (ISRM), Aachen. A.A. Balkema, Rotterdam, vol 2, pp 1335-1338

Panciera A, Piccolo G (1997) TBM scudate-blocco in rocce spingenti. Pubblicazione 12.29, Lombardi Engineering Ltd Minusio

Radoncic N, Schubert W, Moritz B (2009) Ductile support design. Geomech Tunn 2(5):561-577

Ramoni M, Anagnostou G (2006) On the feasibility of TBM drives in squeezing ground. Tunn Undergr Space Technol 21(3-4):262

Ramoni M, Anagnostou G (2007a) The effect of advance rate on shield loading in squeezing ground. In: Underground space-the 4th dimension of metropolises, ITA World Tunnel Congress 2007, Prague. Taylor \& Francis Group, London, vol 1, pp 673-677

Ramoni M, Anagnostou G (2007b) Numerical analysis of the development of squeezing pressure during TBM standstills. In: 
The second half century of rock mechanics, 11 th Congress of the International Society for Rock Mechanics (ISRM), Lisbon. Taylor \& Francis Group, London, vol 2, pp 963-966

Ramoni M, Anagnostou G (2008) TBM drives in squeezing rockshield-rock interaction. In: Building underground for the future, AFTES International Congress Monaco, Montecarlo, Edition specifique Limonest, pp 163-172

Ramoni M, Anagnostou G (2010a) Thrust force requirements for TBMs in squeezing ground. Tunn Undergr Space Technol 25(4):433-455

Ramoni M, Anagnostou G (2010b) Tunnel boring machines under squeezing conditions. Tunn Undergr Space Technol 25(2):139157

Schmitt JA (2009) Spannungsverformungsverhalten des Gebirges beim Vortrieb mit Tunnelbohrmaschinen mit Schild. Heft 89Dissertation, Institut für Grundbau und Bodenmechanik, Technische Universität, Braunschweig

Schneider E, Spiegl M (2008) Convergency compatible support systems. Tunn Tunn Int 40(6):40-43

Schubert W (2000) TBM excavation of tunnels in squeezing rock. In: Lo scavo meccanizzato delle gallerie, mir2000-VIII ciclo di conferenze di meccanica e ingegneria delle rocce, Torino, Pàtron Editore Bologna, pp 355-364

Sellner P (2000) Prediction of displacements in tunnelling. PhD thesis, Institute of Rock Mechanics and Tunnelling, University of Technology, Graz
Shalabi FI (2005) FE analysis of time-dependent behaviour of tunnelling in squeezing ground using two different creep models. Tunn Undergr Space Technol 20:271-279

Simic D (2005) Tunnels de Guadarrama-problématique des tunnels profonds. La traversée de la faille de la Umbria du Tunnel de Guadarrama. Tunnels et ouvrages souterrains $N^{\circ} 190$ - Supplement juillet/août, pp 13-21

Solexperts (2007) HIDCON-Elemente im Tunnelbau. Solexperts AG, Mönchaltorf

Sterpi D, Gioda G (2007) Ground pressure and convergence for TBM driven tunnels in visco-plastic rocks. In: ECCOMAS Thematic conference on computational methods in tunnelling, EURO:TUN 2007, Vienna. University of Technology, pp 89

Sulem J, Panet M, Guenot A (1987) Closure analysis in deep tunnels. Int J Rock Mech Mining Sci 24(3):145-154

Vigl L, Gütter W, Jäger M (1999) Doppelschild-TBM-Stand der Technik und Perspektiven. Felsbau 17 Nr 5:475-485

Vogelhuber M (2007) Der Einfluss des Porenwasserdrucks auf das mechanische Verhalten kakiritisierter Gesteine. Veröffentlichungen des Instituts für Geotechnik (IGT) der ETH Zürich, Band 230, ETH Dissertation Nr. 17079, vdf Hochschulverlag AG Zürich

Wittke W, Wittke-Gattermann P, Wittke-Schmitt B (2007) TBM-heading in rock, design of the shield mantle. In: ECCOMAS Thematic conference on computational methods in tunnelling, EURO:TUN 2007, Vienna. University of Technology, pp 98 